\title{
HOW AWARE OF CHILD SEXUAL ABUSE (CSA) ARE ETHNIC MINORITY COMMUNITIES? A LITERATURE REVIEW AND SUGGESTIONS FOR RAISING AWARENESS IN AUSTRALIA
}

\section{Pooja Sawrikar and Ilan Katz}

Corresponding author Dr Pooja Sawrikar, School of Human Services and Social Work (HSV), Griffith University (GU), Gold Coast campus, Parklands Drive, Southport, Queensland, 4222, Australia, p.sawrikar@griffith.edu.au

Co-author Professor Ilan Katz, Social Policy Research Centre (SPRC), University of New South Wales (UNSW), ilan.katz@unsw.edu.au

Highlights • Ethnic minorities may misperceive child sexual abuse (CSA) as 'a Western problem' • Low awareness results from protecting family name and not discussing sexual matters • Outreach educational preventative programs are required to raise awareness of CSA $\bullet$ Programs must genuinely engage with and empower communities towards child safety

Disclaimer This manuscript has not been published elsewhere, and is not under consideration by any other journal. However, this article reports on the findings from one of six themes explored in a larger study. Thus, content in the Introduction and Method overlaps with content in articles currently under consideration with other journals but which then report on the findings from one of the other explored themes, making them each overall different from one another.

Acknowledgments We would like to thank Professor Fiona Arney, Professor Leah Bromfield, Dr Jen Hamer, and Professor Patrick O'Leary for their comments and feedback on an earlier version. We would also like to thank the anonymous reviewers of this article for their comments and feedback, which have been incorporated into the manuscript.

Conflict of interest There is no known conflict of interest. 


\title{
HOW AWARE OF CHILD SEXUAL ABUSE (CSA) ARE ETHNIC MINORITY COMMUNITIES? A LITERATURE REVIEW AND SUGGESTIONS FOR RAISING AWARENESS IN AUSTRALIA
}

\begin{abstract}
A systematic literature review was conducted to help address the gap in national and international knowledge about child sexual abuse (CSA) and ethnic minority communities. This paper reports the findings of that review in relation to the theme of community awareness. The results suggest that awareness of CSA may be low in ethnic minority communities due to misperceptions that it is 'a Western problem'. This in turn may be associated with norms in the country of origin which are asserted to transfer after migration, such as CSA being seen as a private family matter that does not invite systematic intervention from the state, low media and research attention, widespread acceptance of myths about CSA, and prohibitive norms on discussing matters to do with sex including abuse. Such trends are seen to be the result of, but also then further protect and preserve, collectivist and patriarchal structures. They also make it challenging for raising community awareness. Nevertheless, genuine community engagement through outreach/educational/preventative programs that empower minorities through co-delivery, are high on cultural competency, tailored to specific groups, and use a feminist framework where appropriate, are seen as necessary; they represent investment in minority communities and child safety of children from minority communities. Overall, realistic goals about the effectiveness of outreach educational programs, combined with value for culturally meaningful constructions of child safety, are seen as key toward the success of awareness-raising programs.
\end{abstract}

\section{Keywords}

Child sexual abuse (CSA), ethnic minorities, community awareness, prevention programs, co-delivery, cultural safety 


\section{HOW AWARE OF CHILD SEXUAL ABUSE (CSA) ARE ETHNIC MINORITY COMMUNITIES? A LITERATURE REVIEW AND SUGGESTIONS FOR RAISING AWARENESS IN AUSTRALIA}

\section{$1 \quad$ Introduction}

\subsection{Background, aims, and research questions}

Researchers in the field of child protection recognise that the body of literature on ethnic minorities in Western countries is under-developed (e.g. Bromfield \& Arney, 2008; Burke \& Paxman, 2008; Cashmore, Higgins, Bromfield, \& Scott, 2006; Korbin, 2002; Mildred \& Plummer, 2009; Miller \& Cross, 2006; Thoburn, Chand, \& Procter, 2005; Welbourne, 2002). Compared to the US and UK, Australia is particularly lagging (Sawrikar, 2017a). The literature on child sexual abuse (CSA) and ethnic minority communities in Australia is virtually non-existent; only one such empirical study was found (Taylor \& Norma, 2013). The aim of this article is to address this clear gap in national knowledge by focusing on CSA (one type of child maltreatment) and conducting an exhaustive literature review, to go some way toward building capacity in the area.

Sexual abuse is a taboo topic world-wide, and as such, the silence that surrounds it is cross-cultural. However, this silence further jeopardises the safety of children. Thus, research in the area to help develop knowledge and 'make noise' in the gap that reflects this silence is critical. More specifically, this article addresses two research questions: (1) how aware of CSA are ethnic minority communities in countries like Australia? and (2) if community awareness is low, how can it be raised? They are part of a larger set of research questions that were explored, relating to the improvement of prevention, the encouragement of disclosure, treatment needs, service delivery models, and current national service delivery, but have not been reported on here. Thus, the focus of this paper is on the theme of community awareness.

\subsection{Client group}

Ethnic minorities are defined as migrants who differ from the mainstream in at least one of the four main dimensions of ethnicity - race, language, culture, and religion (O’Hagan, 1999). Thus, in Australia they are differentiated from Indigenous people (Aboriginal and Torres Strait Islander) and Anglos (Saxon/Celtic). They also tend to come from a non-English speaking background (NESB) and countries high on collectivism (see 'Theoretical framework' for more information). In Australia, 'culturally and linguistically diverse' (CALD) is 
the national term of preference. However, 'ethnic minorities' is a synonymous term used here because 'CALD' only highlights issues to do with culture and language, and not racial and religious factors, for this group (Sawrikar \& Katz, 2009).

\subsection{Theoretical framework}

Collective cultures see the family to be the basic unit of society (Hofstede, 1980), so they value social order, harmony, support and roles; the family provides security in exchange for loyalty and obedience; inequality (usually based on age and gender) is seen as appropriate and acceptable; and members tend to be more homogenous as deviations from the norm are not tolerated as greatly (Bond, 2002; Triandis, 1990). They differ from individualistic cultures that see the individual to be the basic unit of society (Hofstede, 1980), so value independence, autonomy, initiative and uniqueness; emphasise that individuals have the right and responsibility to look after themselves; stress horizontal relationships based on equality; and tolerate deviations from the norm to a greater extent (Bond, 2002; Triandis, 1990).

According to the seminal work of Hofstede (2001), the US, Australia, UK, Canada, and New Zealand, all rank (in order) highest on individualism. Western European countries rank next highest, and the remaining parts of the world (e.g. East Europe, Asia, South America, Middle East, Sub-Saharan African, etc.) all rank more highly on collectivism. The implication is that many ethnic minorities in Western countries like Australia originate from non-Western countries high on collectivism.

It is also known from the extensive literature on acculturation that cultural norms, values, and traditions from the country of origin do not simply disappear into a 'melting pot' in the new country. The seminal work of Berry (1980) highlights that migrants continuously manage two conflicting needs - the need to preserve the culture of origin and the need to adapt to the new culture - in response to several variables including dynamic ones. For example, language, generation, age, being visibly different, experiencing racism and discrimination, living in local areas that do not greatly accept diversity, and national and international political discourse, all affect how migrants continuously balance their conflicting needs (Sawrikar \& Katz, 2010; Sawrikar \& Katz, 2009; Sawrikar \& Hunt, 2005). Thus, cultural norms from the country of origin (such as collectivism) remain pervasive, even for well-established migrant groups and across generations.

The theoretical framework of individualism and collectivism is useful because it helps highlight the centrality of family, reputation, patriarchy, silence, and exclusion among victims/survivors of CSA from ethnic minority 
communities. That is, it provides a culturally relevant 'lens' for making sense of their needs and experiences, which is necessary when attempting to identify how best to protect children in these communities. Importantly, the framework is not being used to minimise the importance of these experiences among individualistic groups, which do occur. That is, patterns of silence and exclusion to protect reputation are fundamental in collectivist cultures, but not exclusive to them. These themes and issues are described in more detail under 'Results'.

It is also important to point out that 'individualism' and 'collectivism' are just generalised stereotypes, which occurs because cultures tend to be heuristically categorised as one or the other whereas in fact all cultures exist on a continuum of individualism and collectivism. Thus, they should not be definitively relied on; these broad cultural categories need to be used with vigilance, ensuring that the beliefs comprising the stereotypes are accurate, do not perpetuate harm or disadvantage to groups, and are questioned when applied to individual situations (Sawrikar, 2017a). This is particularly critical for clinical practice because stereotyped assumptions about culture can result in inappropriate and even harmful outcomes (Owusu-Bempah \& Howitt, 2000).

Moreover, there are many ways of examining the role of culture, which can broadly be defined as any "timehonoured tradition that is considered normal, acceptable, and/or of value" (Sawrikar, 2017a, p. 18). As Korbin (2008) puts it, "culture is constantly changing defying easy definitions or the construction of a library-like catalogue of behaviors and values and instead demanding finely nuanced contextual understandings" (p. 122). Thus, the broad or macro-level conceptualisation of culture used here - the distinction between individualism and collectivism - is seen as necessary but not sufficient for understanding CSA among ethnic minority communities.

The association between collectivism and patriarchy is summarised in Table 1. Hofstede (2001) says that the Power Distance Index (PDI) "measures the extent to which less powerful members of organisations and institutions (e.g. the family) accept and expect that power is distributed unequally, so it represents inequality and suggests that a society's level of inequality is endorsed by the followers as much as by the leaders". ${ }^{1}$ Thus, it is a measure of overt inequality. These numbers do not solely reflect inequality based on gender, however power differences between males and females do contribute to these numbers. It is for this reason that as individualism (IDV) goes down, PDI has a tendency to go up but the trend is not completely linear. Overall, this data has been presented to demonstrate that overt patriarchy - the dominance of male power across social systems - does tend to occur in collectivist cultures. (Note: The data in Table 1 has been ranked by countries' IDV score).

\footnotetext{
${ }^{1}$ http://www.clearlycultural.com/geert-hofstede-cultural-dimensions/power-distance-index/
} 
Table 1: Individualism (IDV) and Power Distance Index (PDI) scores by country ${ }^{2}$

\begin{tabular}{|c|c|c|c|c|c|c|c|c|c|c|c|}
\hline Country & IDV & PDI & Country & IDV & PDI & Country & IDV & PDI & Country & IDV & PDI \\
\hline Unites States & 91 & 40 & Czech Republic & 58 & 57 & United Arab Emirates & 38 & 80 & Sierra Leone & 20 & 77 \\
\hline Australia & 90 & 36 & Austria & 55 & 11 & Turkey & 37 & 66 & Singapore & 20 & 74 \\
\hline United Kingdom & 89 & 35 & Hungary & 55 & 46 & Uruguay & 36 & 61 & Thailand & 20 & 64 \\
\hline Netherlands & 80 & 38 & Israel & 54 & 13 & Greece & 35 & 60 & El Salvador & 19 & 66 \\
\hline New Zealand & 79 & 22 & Spain & 51 & 57 & Philippines & 32 & 94 & South Korea & 18 & 60 \\
\hline Italy & 76 & 50 & India & 48 & 77 & Mexico & 30 & 81 & Taiwan & 58 & 17 \\
\hline Belgium & 75 & 65 & Argentina & 46 & 49 & Ethiopia & 27 & 64 & Peru & 16 & 64 \\
\hline Denmark & 74 & 18 & Japan & 46 & 54 & Kenya & 27 & 64 & Costa Rica & 15 & 35 \\
\hline France & 71 & 68 & Iran & 41 & 58 & Portugal & 27 & 63 & Indonesia & 14 & 78 \\
\hline Sweden & 71 & 31 & Jamaica & 39 & 45 & Tanzania & 27 & 64 & Pakistan & 14 & 55 \\
\hline Ireland & 70 & 28 & Brazil & 38 & 69 & Zambia & 27 & 64 & Colombia & 13 & 67 \\
\hline Norway & 69 & 31 & Egypt & 38 & 80 & Malaysia & 26 & 104 & Venezuela & 12 & 81 \\
\hline Switzerland & 68 & 34 & Iraq & 38 & 80 & Hong Kong & 25 & 68 & Panama & 11 & 95 \\
\hline Germany & 67 & 35 & Kuwait & 38 & 80 & Chile & 23 & 63 & Ecuador & 8 & 78 \\
\hline South Africa & 65 & 49 & Lebanon & 38 & 80 & China & 20 & 80 & Guatemala & 6 & 95 \\
\hline
\end{tabular}

${ }^{2}$ http://www.clearlycultural.com/geert-hofstede-cultural-dimensions/individualism/ 


\begin{tabular}{|lll|lc|lcc|c|}
\hline Finland & 63 & 33 & Libya & 38 & 80 & Ghana & 20 & 77 \\
\hline Poland & 60 & 68 & Saudi Arabia & 38 & 80 & Nigeria & 20 & 77 \\
\hline
\end{tabular}




\section{$2 \quad$ Method}

\subsection{Databases, keywords, search terms, and inclusion/exclusion criteria}

The relevant scholarly literature was obtained by following the Preferred Reporting Items for Systematic

Reviews and Meta-Analyses (PRISMA) process. Figure 1 contains the PRISMA flow diagram (Moher,

Liberati, Tetzlaff, Altman, \& The PRISMA Group, 2009).

\section{Figure 1: PRISMA flow diagram}
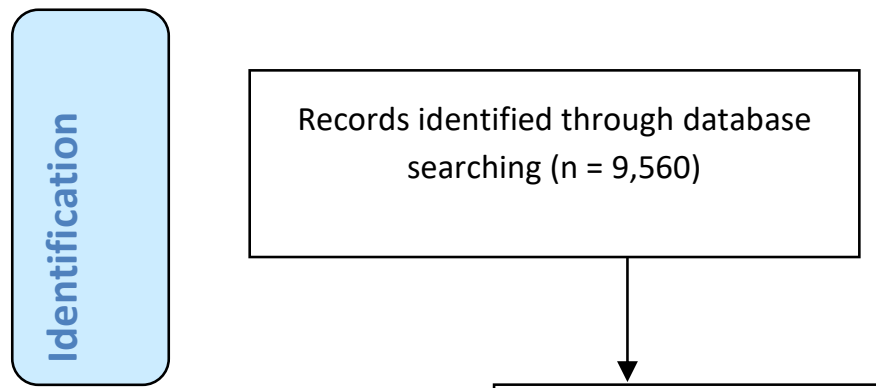

Additional records identified through other sources $(n=4)$ *These 4 'grey literature' records have not been included in this flowchart

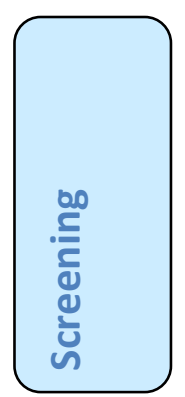

Records after duplicates removed $(n=7,363)$
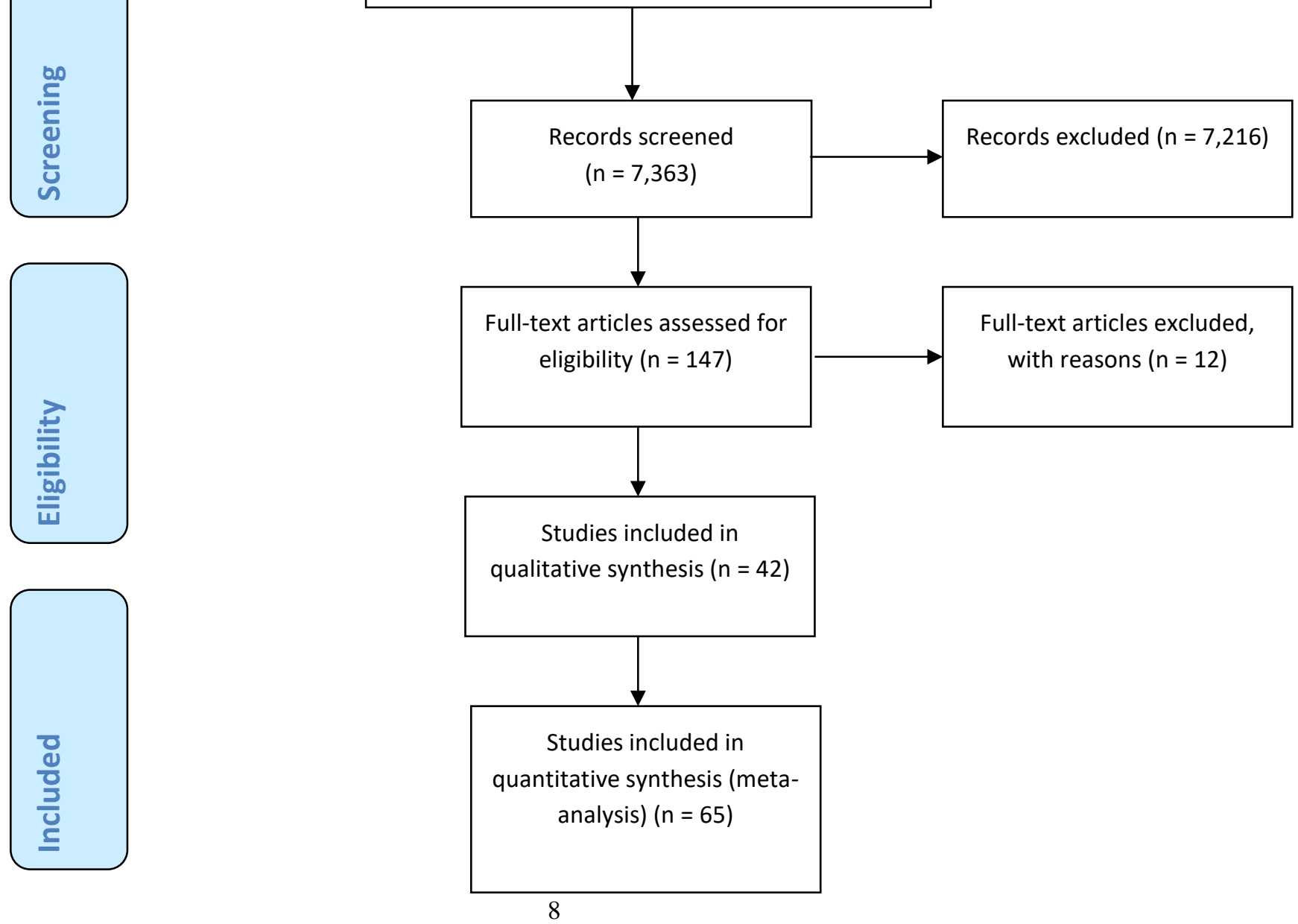
Literature was first sourced from relevant databases. These were: Australian Public Affairs Full-Text, Health and Society Database, Informit Family and Society Collection, Informit Health Collection, Informit Humanities and Social Sciences Collection, Multicultural Australia and Immigration Studies, ProQuest Family Health, PsycINFO, Scopus, Social Services Abstracts, and Sociological Abstracts.

A series of search terms related to the two keywords - 'child sexual abuse' and 'ethnic minorities' - were then combined. Search terms related to the first keyword included: sexual abuse, sexual harassment, sexual exploitation, molestation, rape, indecent assault, sexual violence, and gender violence. Search terms related to the second keyword included: culture (cultur*), race (rac*), culturally and linguistically diverse (CALD), nonEnglish speaking background (NESB), ethnic minority/ies (ethni*), migrant, immigrant, refugee, asylum seeker, of color/colour, and community.

To ensure only recent literature was included, searches were limited to 2000-2016, but seminal research was not excluded if it preceded this date range and was sourced from the reference lists of the recent articles. Only literature in English, peer-reviewed, with the full-text available, and specifically related to sexual abuse experienced in childhood by someone from an ethnic minority background (i.e. ethnic minorities in Western countries or about non-Western countries) was included.

Literature was excluded if it only pertained to Native Americans and African Americans to address a priori issues to do with the transferability of findings from Indigenous groups in other Western countries and/or minority groups not represented in Australia. Literature only pertaining to Latina/Hispanic Americans was also excluded on the grounds that they form a large and significant minority group in the US and so their needs and experiences could be quite specific to that context. Indeed, Kenny and McEachern (2000) found that "many studies (about CSA in minority communities in the US) utilised Asians in their homelands and AsianAmericans, while research examining Hispanics utilised only Hispanic immigrants to the United States" (p. 906). However, literature that addressed groups in addition to Native, African, and Latina/Hispanic Americans for example, Asian-Americans - were included in the review, so that the former groups were not wholly disregarded. This is particularly helpful for ensuring that racial and other ethnic barriers common among all minorities are represented to some extent in the review.

Applying these various inclusion/exclusion criteria left a total of 135 records eligible for full review. Of these, 42 primarily used qualitative methodologies, 65 primarily used quantitative methodologies (including metaanalyses), eight used a mixed-methods approach (counted under the 'Quantitative' records), and 28 used 
secondary analyses (e.g. literature reviews, commentaries, etc.). As the secondary analysis records did not use either qualitative or quantitative methodologies, they do not appear in the flowchart. Only articles relevant to the two research questions have been cited here, and Appendix A contains a summary of these; identifying the ethnic groups investigated in the study, their method, and whether it could be deemed rigorous. The broader literature on 'child maltreatment and ethnic minority communities' and 'family violence and ethnic minority communities' were also drawn upon where relevant, as well as some grey literature (e.g. non-peer reviewed speeches by nationally acclaimed speakers and information found on Australian NGO websites).

\subsection{Strengths and weaknesses}

This review describes all the research (within word limits) that exemplifies each theme identified in the relevant body of literature. Thus, thematic analysis, in addition to the way the literature was obtained, was systematic, comprehensive, and exhaustive. These themes are described in the form of a narrative review under 'Results', and therefore thematic analysis is merged with description. Nevertheless, there are some weaknesses that need to be acknowledged.

The first is that the body of literature itself is small, as already noted. As Futa, Hsu, and Hansen (2001) say, "research focusing on sexual abuse in minority populations is minimal" (p. 190). Tishelman and Geffner (2010) also say, "culture is pertinent to each case of suspected child sexual abuse but only barely (gets) touched on by existing research" (p. 487). This is problematic because it limits being able to offer evidence-based principles of best practice for raising community awareness, with only suggestions being able to be offered.

Another limitation is that the review has grouped several different races, cultures, languages, and religions together, falsely homogenising each of their needs. Fontes (1993) calls this 'ethnic lumping'. It usually occurs because of small sample sizes in research, leading to the need to combine them to be able to say something more representative of the larger category. There is some merit in this - by virtue of being a minority, various groups do have 'a something' in common, making results for one group reasonably generalisable to another. It also has merit at a broad cultural level - many ethnic minority groups are culturally collectivistic, so again cultural trends are likely to be generalisable. Where it has limitations, however, is at the more nuanced and detailed level of culture, language, and religion. Traditions, beliefs, norms, and values about CSA within one group, including how to conceptualise it, speak about it, and address it, will not necessarily transfer to another. For example, Elbedour, Abu-Bader, Onwuegbuzie, Abu-Rabia, and El-Aassam (2006) say "because of the unique characteristics of Bedouin culture (i.e. polygamy, rigid gender roles, sexual taboos), the work that has been 
undertaken on other Palestinian groups cannot be extrapolated to the Bedouin-Arab community" (p. 218). These limitations must be acknowledged, and addressed where possible, as part of ethical conduct in research.

Another issue is that much of the literature is about minority groups in other Western countries, most especially the US and UK, posing issues for the transferability of findings to the Australian context. This issue was somewhat addressed by excluding literature that related solely to groups not represented in Australia (e.g. Native and African Americans), however caution still needs to be exercised. Reasonable comparisons can be made with countries like the US, UK, Canada, and New Zealand, however they do still have different 'ethnic profiles' to Australia, with different specific groups and sizes comprising their migrant community, as well as reasons for their migration to these countries, which all affect their socio-cultural and political standing there (Sawrikar \& Katz, 2008).

There is also the issue that themes identified in the literature from non-Western countries may only partially help explain the needs and experiences of ethnic minorities in Western countries. This is because the migration experience interacts with cultural factors from the country of origin to making literature 'back home' possibly limited or even irrelevant. Moreover, literature from non-Western countries is not equally represented; most of it is about East Asians and South Asians, sub-Saharan and South Africans, and Arabs and Jews. Thus, the experiences of other groups are even less well documented.

These limitations pose further issues for transferability to the Australian context. Twenty six per cent of Australia's population are born overseas (Australian Bureau of Statistics [ABS], 2016). In order, Australia's largest migrant groups from non-English speaking countries of origin are from China, India, Philippines, Vietnam, Italy, South Africa, and Malaysia (ABS, 2016). There has also been a recent increase in the number of people from Africa, commonly entering on humanitarian visas (ABS, 2012). The data in Table 2 summarises Australia's overseas-born population. Overall, it highlights that the current non-Western literature is helpful but not sufficient to cover the breadth of applicability required.

It is also important to point out that only including English-language articles is problematic because it leaves out important voices from within countries of origin, which future research by multilingual scholars can and should address. Overall, however, the inclusion of articles from diverse backgrounds is a global approach consistent with and required for issues that address multiculturalism. Indeed, the dearth of research in Australia means that this review has to borrow from overseas to be able to begin national knowledge-building. 
Table 2: Overseas country of birth by region (ABS, 2016)

\begin{tabular}{|c|c|c|}
\hline Region of birth & Persons & $\begin{array}{l}\text { Proportion of overseas-born } \\
\text { population }(\%)\end{array}$ \\
\hline North-West Europe & $1,431,169$ & 23.2 \\
\hline South-East Asia & 872,891 & 14.2 \\
\hline North-East Asia & 789,436 & 12.8 \\
\hline Southern and Central Asia & 782,903 & 12.7 \\
\hline Southern and Eastern Europe & 657,698 & 10.7 \\
\hline Oceania and Antarctica(a) & 657,696 & 10.7 \\
\hline Sub-Saharan Africa & 317,182 & 5.1 \\
\hline Middle East & 303,089 & 4.9 \\
\hline Northern America & 129,704 & 2.1 \\
\hline South America & 114,599 & 1.9 \\
\hline Other Americas ${ }^{\mathrm{a}}$ & 21,751 & 0.4 \\
\hline North Africa & 70,994 & 1.2 \\
\hline Total $^{b}$ & $6,163,667$ & 100 \\
\hline
\end{tabular}

Source: Census of Population and Housing, 2016; a - Other Americas includes Central America, Caribbean and Americas, nfd; b - Total includes Inadequately described, At sea, and North Africa and the Middle East, nfd.

\section{$3 \quad$ Results}

The results of the literature review suggest that awareness of CSA is likely to be low in ethnic minority communities in countries like Australia. This in turn appears to be due to three main inter-related trends in the country of origin - 'legal and social complacency', widespread myths about CSA, and preservation and protection of patriarchal structures. These can lead to low awareness and risk perception of CSA, which are asserted to carry over (to greater or lesser extents for individuals) after migration. This assertion is linked to the literature on acculturation which shows that norms, traditions, beliefs and values do not simply disappear after migration, and therefore is circumstantial and subject to individual variation but also cogent or logically reasonable for describing broad trends. 
The three aforementioned trends in the country of origin can make raising awareness challenging, due to misperceptions that CSA is not relevant to their community. This challenge is exacerbated by prohibitive norms regarding the discussion of all matters to do with sex including abuse. These barriers to raising community awareness, as well as suggestions for how to raise it, are described below.

\subsection{Barriers to raising awareness \#1: Low perceived relevance}

\subsection{1 'Legal and social complacency' in the country of origin}

Ethnic minorities may originate from countries that do not legally recognise CSA, or child maltreatment more broadly, as a crime. Alternatively, they may originate from countries where the legal prohibitions against CSA are seldom enforced. Such situations reflect what could be called 'legal complacency' (a term we are introducing ourselves). As an example, Al-Fayez, Ohaeri, and Gado (2012) say, "in Arab countries, there are enormous cultural obstacles that make society complacent about child (sexual) abuse ... Officially, its existence is not admitted. The existing laws on child welfare should be updated to recognise that the problem exists, make legal provisions for protecting children, prescribe ways for helping families, and specify punishment for adult offenders" (p. 53, 63).

Lack of legislation or child protection systems in countries of origin are not direct indicators of low awareness among minority communities in countries like Australia, but they can point to an underlying reluctance to acknowledge CSA in those countries, which can carry over after migration. In particular, the reluctance may reflect confusion about the role of governments in what has long been seen as a 'private family matter' (and affecting perceptions of the role of Australian governments, especially among new arrivals). As ShalhoubKevorkian (2000) puts it, "while societies in North America and Europe have transformed the issue of abuse from a private one to a social problem, calling for responsible social policies to prevent and combat such violence, Asian, African, and other non-Western societies remain in the midst of a struggle regarding the social responsibility and accountability of the state” (p. 621). Similarly, Liao, Lee, Roberts-Lewis, Hong, and Jiao (2011) say, "unfortunately, the prevailing viewpoint continues to hold that child maltreatment is a private affair within the family, and therefore, the government should not intervene. However, this viewpoint is challenged by growing research evidence regarding the prevalence of maltreatment (in China but also elsewhere) and the negative sequelae of child maltreatment" (p. 1709). 
Arguably, governments in collectivist countries of origin struggle because recognition of children's rights (including that of safety) requires re-distributing the power normally bestowed to adults over to children, and this is a substantial and confronting change in and challenge to basic cultural beliefs that underlie the structure of collectivist societies. As it is, “child abuse is a social concept that continues to evolve as children's rights are recognised by society" (Yiming \& Fung, 2003), but this evolution could be slower in collectivist cultures because it requires ceding power from adult males, who benefit from long-standing traditions that place them, and continue to keep them, at the top of the 'power hierarchy' (see '3.1.2 Myths about CSA' and '3.1.3 Preservation and protection of patriarchal structures' for more information).

Lack of legal recognition of CSA as a crime may be reinforced by other legal trends that also reflect 'complacency'. For example, several countries have voluntary rather than mandatory reporting, such as Singapore (Yiming \& Fung, 2003), Israel (Ajzenstadt \& Cavaglion, 2005; Elbedour et al., 2006), and Ghana (Boakye, 2009). Lack of mandatory reporting itself is not a cultural barrier to awareness of CSA, as some Western countries such as the UK and Ireland do not have mandatory reporting laws but do have high awareness of CSA, however it can interact with other factors that maintain low awareness. Poor record keeping about victims and lack of systematic mechanisms for reporting abuse, and sharing statistics and official records, were also noted in various countries such as Lebanon (Usta \& Farver, 2010), Singapore (Back, Jackson, Fitzgerald, Shaffer, Salstrom, \& Osman, 2003), Papua New Guinea (Lewis, 2012), the Philippines (Sugue-Castillo, 2009), and Jamaica (Gibson, Emeka, \& Walters, 2007).

The main risk of 'legal complacency' is that it can then lead to 'social complacency'. For example, Gibson et al. (2007) say that in Jamaica, "despite the Child Care and Protection Act being implemented in 2004, incest remains a mere misdemeanour" (p. 116). In the "Bedouin-Arab community in Israel, sexual abuse is a highly volatile, unspoken topic, and (so) the few existing reports only represent the most flagrant, extreme cases, which fail to capture the true scope of the social problem" (Elbedour et al., 2006, p. 216). In China, there is some increased reporting (Shang \& Katz., 2014) but overall there are only "a limited number of media reports on child maltreatment” (Liao et al., 2011, p. 1710). In a case study of the 'HIV virgin cure myth', Meel (2003) says, "the response of society (in South Africa) to cases of rape is of grave concern. A victim reports a case of rape to an authority and is further degraded for her troubles. There is collective indifference and amnesia about the rape in the community" (p. 87). In Tanzania, "community passivity has contributed to injustice by not providing support to victims and not cooperating with the investigation process" (Kisanga, Mbwambo, Hogan, 
Nystrom, Emmelin \& Lindmark, 2010, p. 303). Liao et al. (2011) say that the public's lower awareness of the severity of CSA in China can "generate apathy and increase the public's tolerance and acceptance of maltreatment" (p. 1715).

It is important to note that not all trends reflect 'legal and social complacency' in these various countries. For example, in the Philippines, "the death penalty is mandatorily imposed for incestuous rape" (Sugue-Castillo, 2009, p. 194-195), indicating the most severe consequences for the crime. Several countries such as India and Pakistan (Gilligan \& Akhtar, 2005), Jamaica (Gibson et al., 2007), South Africa (Vermeulen \& Greeff, 2015), Tanzania (Lalor, 2004a), and other African countries (Rwanyonga, Mike, \& Nakubulwa, 2009) have nongovernment organisations (NGOs) that specialise in protecting children from child abuse (broadly) and child sexual abuse (specifically). There are also individuals from these countries who are highly vocal about and advocate for human rights and social justice. For example, Sossou and Yogtiba (2009) say, "we consider abuse of children, in whatever form, to be an endemic social problem (of West Africa) that demands urgent attention and total commitment from the national governments in the sub-region. The apparent lack of governmental commitment of resource allocations, enforcement of laws, and the development of comprehensive children and family welfare programmes to protect children have endangered the psycho-social development of (these) children" (p. 1219). UNICEF (2008) also has a very strong program of working with governments around the world and has introduced child protection systems in a number of countries internationally as well as raising awareness in communities across the globe. Thus, the legal position in countries of origin of ethnic minority communities may give a clue to the social attitudes towards CSA in those societies, however due to such exceptions, there is no direct relationship between the legality of CSA in the country of origin and awareness of or attitudes about CSA in different minority communities in Australia.

Despite exceptions, the overall trend in (usually non-Western) countries is that of 'legal and social complacency'. Perhaps the strongest evidence of this is the comparatively low amount of research conducted on the prevalence of CSA in these countries, compared especially to countries like the US and UK. Unfortunately, Australia has also not conducted a national prevalence study of child maltreatment or CSA (Mathews et al., 2016), consistent with its poor research base in the area. However, overall, that research is greater in Western countries can give the false impression that CSA is a 'Western problem' (Gilligan \& Akhtar, 2005; Ko \& Koh, 2007). 
Several examples of this misperception were identified in the literature. AlMadani, Bamousa, Alsaif, Kharoshah, and Alsowayigh (2012) say "in Saudi society, the violation of personal dignity by means of sexual crimes was a hidden subject nobody wanted to discuss ... (but) the notion that child abuse and neglect are rare in Arab countries is a myth that can no longer withstand the strength of the evidence. Denial is unacceptable" (p. 34-35). Ko and Koh (2007) say, "people in Korea have commonly thought, until recently, that CSA was extremely rare, and that if it did happen, it happened in Western countries where the perpetrators were men who were mentally ill” (p. 1166). Gilligan and Akhtar (2005) say, "the incidence and impact of CSA have been increasingly recognised in (South) Asian countries (like) Pakistan, India, and Bangladesh ... (which) is helpful in providing factual information to challenge suggestions that sexual abuse is only a 'western' problem or a phenomenon which results primarily from 'the unIslamic sexual norms of the West'” (p. 270). Brophy, JhuttiJohal, and Owen (2003) found that "White families (in the UK) are more likely to be referred for CSA concerns ... but when 'point of referral' studies are compared to those that (actually) reach court proceedings, sexual abuse is found to be a major reason for referral among children of mixed heritage (27\%) and South Asian children (19\%), compared with White (6\%) and Black (3\%) children” (cited in Chand \& Thoburn, 2006, p. 374). Finally, McGuffey (2008) reports: "All the black and Puerto Rican parents in this study (in the US) repeatedly spoke of CSA as "something that happens to white folks" because people of colour often view sexual deviancy as a part of white culture ... A black father, was shocked when it came out that his son had been sexually abused for over two years by his own uncle" (p. 231).

In short, "sexual abuse occurs within all types of families and affects all cultures and races" (Kenny \& McEachern, 2000, p. 905); it is not solely a Western phenomenon. As Allimant and Ostapiej-Piatkowski (2011) put it, "we know that demographics such as levels of education, socio-economic status, age, familiarity, and religious beliefs make no difference to descriptors of a perpetrator of abuse ... violence and abuse can occur in all families" (p. 3-4). "Some authors assert that child abuse, and specifically incest, has existed at all times in all societies. (Indeed), data consistently demonstrates that the perpetrator is most likely to be a family member (42\% parent, 22\% a relative)" (Kenny \& McEachern, 2000, p. 905).

Research suggests that the prevalence of CSA is lower in China than in other countries. For example, a recent meta-analysis of studies with Chinese samples by Ji, Finkelhor, and Dunne (2013) placed the prevalence of contact CSA for females at $9.5 \%$ and for males at $8.0 \%$, suggesting that rates of contact CSA are on par with 
those found world-wide, but they also found that the "international rate of penetrative child sexual abuse of females has been estimated at $15.1 \%$ and greatly exceeds the Chinese women's rate of just 1\%" (p. 619).

In the social context of Chinese culture, which is "very conservative regarding sexual attitudes and practices, especially where young people are concerned, there is a prevailing belief that children and adolescents do not and should not have sexual experiences, (so) the findings (of lower prevalence) reinforce the norm" (Chen, Dunne, \& Han, 2004, p. 1181). Indeed, "past researchers have not focused their attention on CSA in AsianAmerican populations, believing that due to religious and cultural values, it does not exist in these populations" (Kenny \& McEachern, 2000, p. 908).

Nevertheless, there is a risk that lower prevalence - genuine or apparent - may be used as evidence for placing the issue of CSA low on institutional/governmental priority, and in turn, risk citizens and communities being unaware of the size or severity of the crime. As Liao et al. (2011) put it, "despite the empirical evidence, the Chinese Government and policy makers have given little attention to the issue of child abuse. The fact that there has been no attempt to develop a legal definition of maltreatment exemplifies the low priority the Chinese Government has accorded this issue ... The interplay of cultural practices and values obscures the gravity of the situation and allows negative practices to thrive and flourish" (p. 1709, 1717).

Thus, in China but also elsewhere, the "depth and seriousness of child sexual abuse, and as a globally prevalent phenomenon, is yet to be realised" (Karthiga \& Ravikumar, 2014, p. 728). Indeed, the research shows that it is difficult to recruit adults to participate in CSA prevention programs even in Western countries (Tang \& Yan, 2004), but this may be particularly so in ethnic minority communities because of a false belief that the risk of CSA is low in their community.

\subsubsection{Widespread acceptance of myths about CSA in the country of origin}

'Legal and social complacency' in the country of origin is not the only factor that can contribute to low awareness of CSA among minorities after migration. It can work in conjunction with widespread myths about CSA in the country of origin, which may also transfer after migration. Such myths may include, for example, that 'sexual contact between an adult and a child which is wanted by the child and which is physically pleasurable for the child cannot really be described as abuse', 'sexual contact with an adult can contribute favourably to a child's subsequent psychosexual development', 'most children are sexually abused by strangers or by someone who is not well known to the child', 'children who act in a seductive manner must be seen as 
being at least partly to blame if an adult responds to them in a sexual way', 'a woman who does not satisfy her partner sexually must bear some of the responsibility if her partner feels frustrated and turns to her children for sexual satisfaction', 'child sexual abuse takes place mainly in poor, disorganised, unstable families', 'boys are more likely than girls to enjoy sexual contact with adults and are therefore less likely to be emotionally traumatised by the experience', and 'children who do not report ongoing sexual abuse must want the sexual contact to continue' (Collings, 1997, cited in Collings, Lindblom, Madu, \& Park, 2009).

The research suggests that females are at greater risk of CSA than males world-wide, at a reported ratio of up to 3:1 in some studies (Chen et al., 2004; Wang \& Heppner, 2011) and 4:1 in others (Krug, Dahlberg, Mercy, Zwi, \& Lozano, 2002; Thornton \& Veenema, 2015). Females also report more severe sexual assault that is coupled with violence (Freeman \& Temple, 2010). Thus, acceptance of myths about CSA “effectively condones, justifies, and/or excuses sexual assault" (Collings et al., 2009, p. 9); making "females somehow complicit in victimisations" (Gibson et al., 2007, p. 111) helps preserve and protect the status quo of higher social power for males. In other words, the main purpose and effect of these myths is to shift culpability for the crime from the (usually male) perpetrator to the (usually female) victim. In this way, myths about CSA are seen to help protect and preserve patriarchal structures.

Indeed, 'rape myths' - which operate similarly to myths about CSA and which are defined as "mechanisms that people use to justify dismissing an incident of sexual assault from the category of real rape" (Walker \& Bright, 2009, cited in Karsli \& Anli, 2011, p. 501) - occur in all cultural groups, and in both genders. For example, women may endorse rape myths such as "some people 'deserve' rape due to their way of clothing" (Karsli \& Anli, 2011, p. 501) because they act as a self-protective mechanism to reduce their degree of perceived risk or susceptibility to it. As one participant in the study by Jewkes, Penn-Kekana, and Rose-Junius (2005) said: “When my father, uncle or brother is there I don't wear tight trousers, because if they rape me, (then) I can't blame them" (p. 1813). However, as Gibson et al. (2007) say, the myth that "females provoke victimisation by their clothing, seductiveness, and flirting may be dispelled by noting that in 1998, the youngest sexual abuse victim in Jamaica was 2 months and the oldest 83 years" (p. 112). Thus, negative stereotypic myths about CSA held by women are seen to be the result of 'patriarchate socialisation'; a term we are introducing to highlight that the internalisation by females of myths about CSA and rape myths are the result of social factors that favour and protect male perpetrators, through a shifting of culpability to the usually female victim. 
Importantly, myths about CSA and their ensuing protection of patriarchal structures are not exclusive to nonWestern/collectivist cultures. Taylor and Norma (2013) conducted a study on Anglo Australian women survivors of CSA and found that participants "experienced a range of denials, including explicit denials, trivialising and minimising harm, and casting the victim as (mentally) unstable and thus unreliable" (p. 120). These all demonstrate how perceived culpability of the crime can be shifted onto the (usually female) victim, even in Western/individualistic groups.

\subsubsection{Preservation and protection of patriarchal structures in the country of origin}

Patriarchal structures are pronounced in collectivist cultures because hierarchical power is overtly bestowed to adults and males. Thus, child victims from these groups (especially female) may be at risk of suffering gendered abuses of power. The literature was rife with examples of gender inequality and oppression in various collectivist cultures.

In Israel, "the patriarchal structure of society and of the family continue to dominate contributing to the reproduction of inequality in women's socio-economic status and power" (Ajzenstadt \& Cavaglion, 2005, p. 257). Sherer (2009) reports that Israeli Arab males, more than Jewish ones, view violence in a marriage as a legitimate way of solving problems, and "wife abuse is justified by both males and females when wives fail to live up to traditional role expectations" (p. 13).

"Until the early 1990s, intimate partner violence (IPV) in Japan was considered a personal matter rather than a social problem or crime, and the general public tended to tolerate or rationalise a husband's use of violence against his wife" (Yoshihama \& Horrocks, 2010, p. 29). In South Asian communities, there is a "cultural acceptance of men's sexuality, but not women's, the dutiful rights of a man to have sex with his wife at will, and the tolerance of unwelcome sex by women. There are also issues of women having to protect their honour (by being) loyal to their family and marrying a partner chosen for them by their parents" (Reavey, Ahmed, \& Majumdar, 2006, p. 178). Singh (2009) further reports that, after migration to Western countries like the US with more flexible gender roles, the loss of patriarchal power and the "new power dynamics for South Asian men may cause them to enact anger and frustration (in the form of) violence against women, such as sexual abuse" (p. 363).

In Latin America, there is the culture of 'machismo', in which "the cultural ideal of masculinity is associated with pride and inherent value in the man's ability to protect, support, and provide for his family. In machismo 
cultures, children are expected to obey the instructions of men (and) this introduces the potential for power abuse by older males" (Thornton \& Veenema, 2015, p. 436). In one study in the Caribbean, "several examples were cited of fathers who abused their children, with the rationale that children were their property and they were doing no harm" (Pasura et al., 2012, p. 209).

In Bangladesh, Fattah and Kabir (2013) say, "the high prevalence of CSA by male perpetrators reflects that males are socialised to be more aggressive. By the time they reach adolescence, they are also deeply inculcated into a system of male entitlements including entitlement to sex and attitudes about the sexual availability of females and children ... The state's failure to provide authoritative prohibition contributes to an implicit social tolerance toward CSA. Societal acquiescence in the long run is perpetuating a condition in which girls grow into women with gendered subjectivities in which sexual assault and harassment by males are part of everyday life" (p. 909, 912).

In Taiwan, "a woman who survives acquaintance rape is still encouraged to marry her rapist to preserve her chastity" (Luo, 2000, p. 583). Expectations to marry a rapist were also reported in Papua New Guinea (Lewis, 2012), Zimbabwe (Lalor, 2004b), and in Arab and Muslim countries (Shalhoub-Kevorkian, 2000). Interestingly, parents in patriarchal societies may marry their daughter off early as a form of protection from sexual harassment. For example, Fattah and Kabir (2013) found, "that only eight girls (in their study in Bangladesh) were reported to be married from among the 713 reported victims of child rape and attempted rape” (p. 909). They argue that "compared to unmarried girls, married girls may be less vulnerable to sexual abuse because perpetrators have a preference for unmarried girls, motivated by the high value placed on virginity” (p. 909). In Dhaka city, Bangladesh " $65 \%$ of girls get married before reaching the age of 18” (Fattah \& Kabir, 2013, p. 909). While parents may engage in the cultural norm of early marriage out of reasons to protect their children, unfortunately, child marriage is also abusive to children (Lewis, 2012).

Also in Bangladesh, it was found that a different word for rape was used when the victim was male or female (Fattah \& Kabir, 2013). "Reports on rape or attempted rape of a girl mention the word dhorshon, the most commonly used and understood Bangla word for rape; in contrast, for male children the word used is bolatkar, a comparatively low frequency word for rape. A victim of dhorshon loses her social status, is heavily stigmatised, and often has to take full or equal share of the blame. A victim of bolatkar is gradually forgiven, and his social status can be regained with time ... (Because of) stereotyped gender roles constructed by the patriarchal power 
structure, it becomes necessary to use a different word as the boy is positioned higher in the hierarchy of social power relations" (p. 910).

In Ghana, "the myth that males are incapable of controlling their sexual desires" (Boakye, 2009, p. 959) is reported. For example, a male police officer, in regards to institutional responses to adult sexual violence in Ghana, said "when a man is in heat [sic], hot like a frying pan, and a woman refuses him sex it is brutal" (Boakye, 2009, p. 959). This is not exclusive to African countries. In Sheik Taj din al-Hilaly's "notorious and misogynistic" (Pether, 2009, p. 254) sermon, given in September 2006 at a Lakemba Mosque in Sydney, he said “when it comes to adultery [his words, and in relation to a rape case that was being heard at the time], it's 90 per cent the woman's responsibility because she owns the weapon of seduction" (Henderson, 2007, p. 9).

In Zimbabwe, "men are considered to be superior to women and older people have authority over younger ones. This double authority does not seem to lead to a sense of responsibility: men seem to feel that a "real" man cannot be expected to control his sexual desires, shifting responsibility for male lust to girls. Male dominance in society (is also a cause for the prevalence of) sexually abused children infected with HIV and STDs" (Madu \& Peltzer, 2000, p. 264).

The Kuleana Centre for Children’s Rights in Tanzania similarly says: “a society in which children have little status or power, and no voice, is a society that makes its children extremely susceptible to sexual abuse and HIV infection. In this sort of society CSA is not an aberration, but an inevitable consequence" (1997, p. 4, cited in Lalor, 2004a, p. 837). Even the Government of the United Republic of Tanzania acknowledges that "the poor situation currently facing women is a result of gender discrimination and oppression. (Because) society values boys more than girls ... (these) affect her survival, protection, and development, including gender discrimination in education, female genital mutilation which endangers her health and can cause her to be infected by HIV/AIDS, early pregnancy, and mistreatment such as rape, defilement, harassment, molestation, and abuse" (1996, p.8, cited in Lalor, 2004a, p. 837).

"Another form of sexual abuse, peculiar among the Ewe-speaking people of Ghana and Togo, is the "trokosi practice'. Trokosi is a traditional fetish practice in which young virgin girls, as young as 10, are sent to fetish shrines as slaves to atone for the sins and crimes committed by their relatives, who are usually already dead. This system, based on traditional religious beliefs, is discriminatory against young girls who are mostly denied any chance of formal education and health care, and often, are sexually abused and impregnated by the custodial fetish priests in the shrines" (Sossou \& Yogtiba, 2009, p. 1223). 
"The condition of females in Palestinian society is a harsh one. Patriarchal beliefs suggest that females are of less value (and) that a woman is a burden - a source of troubles because of her seductive nature and her tendency to bring shame on her family if she "misbehaves". (Thus), blaming the victim is embedded in sociopolitical and cultural codes (that are) part of an oppressive and exploitative cultural and patriarchal paradigm" (Shalhoub-Kevorkian, 2000, p. 622).

Haj-Yahia and Tamish (2001) also say that "the patriarchal perspective of Arab society not only advocates male dominance and subordination of women, but also views females as a source of evil, anarchy (fitna), and trickery and deception (kaid). (Thus), besides exceptional cases, such when they are very young girls who have no way of defending themselves, or women can prove beyond any doubt that they tried to defend themselves, that they were dressed in modest, traditional attire, and that they behaved humbly without doing anything that could have 'invited' the perpetrator to exploit them, (then) the prevailing tendency is to blame the victim for her situation, on the grounds that 'women who don't ask to be raped will never be raped"” (p. 1304).

"In tribal Bedouin society, the rights of females to make personal choices, receive an education, and pursue selfactualisation are all invalidated by the imperative to protect the family's honour against even the suspicion of sexual threat. (Thus), Bedouin girls are less likely to complete high school; many drop out at their parents' request, to avoid bringing dishonour to their families (that would be incurred) by leaving home alone (for school). This is (particularly) unfortunate because successful academic experiences play a protective role in preventing (sexual) aggression and victimisation ... Positively, however, urbanisation and the influence of westernised Israeli culture is allowing Bedouin women to become more assertive in questioning traditional Bedouin values and becoming more empowered to challenge the practice of forced marriage in early age and their secondary roles in the patriarchal culture" (Elbedour et al., 2006, p. 217, 219).

"Modesty in dress is encouraged for both females (veil or hijab) and males among observant Muslims, and messages about masculine and feminine stereotypes may result in dichotomies between what is acceptable and shameful ('virgin' vs. 'whore' dichotomies). These dichotomies echo the values that mark many Arab nations, where the consequences of sexual unfaithfulness may be honour killings in order to reinstate familial honour" (Haboush \& Alyan, 2013, p. 507). At worst, therefore, "acts that terminate the sexual purity of women may be perceived as crimes of honour" (Salter, 2014, p. 106), and result in their death. "The UN estimates (that) 5,000 women are being killed each year in the name of 'honour' (UNFPA, 2000)” (Meetoo \& Mirza, 2007). 
Many of the aforementioned examples of gendered inequality and oppression focus on CSA, but they can be extended to explain the occurrence of family violence too (as already suggested). That is, young females can grow up in environments that condone the further traumatisation of the victim, which helps protect and preserve the male perpetrator's power (Allimant \& Ostapiej-Piatkowski, 2011; Henderson, 2007). Thus, when females live with these social norms and discourse on an everyday basis, it can affect the way they perceive and interpret their abuse, including possibly failing to recognise CSA as a crime. For example, Allimant and OstapiejPiatkowski (2011) say, "there may be a strong pattern of socialisation of young (immigrant) girls, communicated both verbally and modelled by mothers and grandmothers, that girls and women have to obey and conform to traditional rules ... (that) create a sense of obligation to stay in a sexually violent marital relationship, and to not see it as a "real" crime" (p. 6,9). Instead, "rape and child marriage where girls are raped on their wedding night ... (are termed as acts of) adultery (in the Arab community)" (Henderson, 2007, p. 10).

Sometimes, victims do recognise that a crime has been committed but because of social norms, leaving is not an option. Sherer (2009) says, "most Israeli Arab females do not agree that in certain situations husbands have the right to beat their wives" (p. 13). However, as Allimant and Ostapiej-Piatkowski (2011) point out in the context of help-seeking for family violence, "there is great diversity in the way violence is perceived, understood, and incorporated into individual women's worldviews. The necessity to comprehend the violent experience constitutes their basic need in seeking support. While they recognise the violence is occurring, (it is made sense of within) a world-view that does not include options for women who experience sexual violence by their husbands" (p. 6, 7).

Overall, Karthiga and Ravikumar (2014) point out that "childhood is a lengthy period of apprenticeship and secondary status in most human societies, (but) in the case of male children, this condition is short lived. Boys come into a state of power that allows them considerable authority over others. Thus, female childhood nurtures a state of powerlessness and dependency" (p. 728).

In the end, "failure to convict sexual abusers sends a silent message not only to the perpetrators but also to society as a whole that it is possible to get away with rape. In turn, this belief strengthens males' sense of entitlement over their environment, leaving children, particularly females, vulnerable to sexual abuse" (Fattah \& Kabir, 2013, p. 912).

3.2 Barriers to raising awareness \#2: Not discussing any matters to do with sex including abuse 
So far, the literature indicates that socio-cultural norms in countries of origin could lead to minimisation of the seriousness of CSA and low perceived risk of the threat of CSA. It may even lead to failure of recognising it as a crime. For example, Singh, Hays, Chung, and Watson (2010) reports: "Mira (pseudonym) was sexually abused by both her uncle and her brother. She stated that she "somehow deserved the abuse because she had not been taught to value her body as her own" as a female in South Asian culture" (p. 448). Thus, there are already several and significant barriers to raising community awareness. However, there is another significant barrier to raising awareness of CSA in ethnic minority communities, and that is norms that prohibit discussion on all matters to do with sex including abuse.

This taboo is noted widely across cultures. For example, it was reported in Puerto Rico (Kenny \& McEachern, 2000), China (Chen, Dunne, \& Han, 2007; Chien, 2013), Southeast Asian communities (Futa et al., 2001), Israel (Elbedour et al., 2006; Lev-Wiesel \& Amir, 2005), India (Karthiga \& Ravikumar, 2014), Taiwan (Wang \& Heppner, 2011), Africa (Masehela \& Pillay, 2014), among Dutch Antillean/Surinamese minorities (Okur, van der Knaap, \& Bogaerts, 2016), in Arab American communities (Haboush \& Alyan, 2013), in South Asian Muslim society in the UK (Chand \& Thoburn, 2006), and among CALD women in Australia (Allimant \& Ostapiej-Piatkowski, 2011).

As matters to do with "sexuality and sexual activity are not open for discussion outside of the family and certainly not with children" (Narducci, 1992, p. 17, cited in Chand \& Thoburn, 2006, p. 373), this even affects the availability of appropriate vocabulary in native tongues. For example, in a study by Narducci (1992) "there were no comparable terms within Bengali to describe sexual abuse. 'This led to a situation which involved staff having to imply that sexual abuse had occurred by referring to a 'bad thing' having happened, followed by crude descriptive details of the actual abuse itself' (p. 17)" (cited in Chand \& Thoburn, 2006, p. 373). Gilligan and Akhtar (2005) similarly reported: “'This word 'tashadud', what does it mean?' asked several (South Asian) Urdu-speaking colleagues and would-be respondents (in Bradford, UK) to a questionnaire headed 'Jensi Tashadud Ke Bare Mein Baat Keyja' (Sexual abuse is something we need to talk about). 'I've never heard it before', they said" (p. 267-268).

\subsection{Suggestions for raising community awareness}

Despite that raising awareness is likely to be challenging, it is still seen as necessary because it reflects active engagement with, and thus investment in and commitment to, protecting children from Australia's minority groups, in ways that are sensitive to their unique cultural needs and context. Based on the findings of the 
literature review, one suggestion for raising community awareness is offered - the delivery of outreach/educational/preventative programs. This is consistent with the family violence literature, which also calls for outreach programs in minority communities (Whitaker et al., 2007).

It is further suggested that these programs be co-delivered by service providers in organisations and members of ethnic minority communities who strongly advocate for human rights and social justice (Williams, 2014), be piloted to ensure they were culturally tailored to specific groups, be high on cultural competency, and consider using a feminist framework. These characteristics are described in more detail below.

\subsubsection{Co-delivering programs - Service organisations and community members}

The use of community members is critical in outreach programs because it reflects community-based action and participatory empowerment (Itzhaky \& York, 2001; Reid, Reddock, \& Nickenig, 2014). Thus, change for fairness, equality, and safety would be 'stirring from within', as suggested by NGOs such as the Australian Muslim Women's Centre for Human Rights (AMWCHR). It would also "capitalise on the courage and creativity of "third-world feminists", , as described by the Australian human rights activist Randa Abdel-Fatah in a speech she delivered on International Women's Day in Sydney 2016. It helps send a strong message that the community acknowledges there is an issue with CSA and that they are taking steps to address it. Importantly, such individuals may be new arrivals or more established first, second, or third generation Australians, so recruitment of community members would need to be wide-reaching.

As already stated, the larger study explored current service provision in Australia (the results of which have not been described here as the focus of this paper is community awareness). One key finding, however, was that national service organisations do not currently play a significant role in raising community awareness of CSA among ethnic minority groups. Thus, co-delivery of outreach programs would mobilise organisations to help contribute to this goal. Co-delivering also offers an opportunity for exchange - community members can become better informed of the roles and responsibilities of service organisations in the clinical setting and service providers can obtain cultural training.

Importantly, (and again derived from the literature reviewed in relation to all six themes; outside the scope of this paper), programs would need to be co-delivered with all types of service organisations - ethno-specific, multicultural, and mainstream - to help send the message that culturally sensitive support is available from service providers from a range of backgrounds. This is critical because victims/survivors may fear a breach of 
confidentiality from an ethnically-matched service provider and so opt for a non-matched provider (Sawrikar, 2017a) who would still need to be informed of issues relevant to the provision of culturally sensitive treatment.

\subsubsection{Piloting - Culturally tailored programs with appropriate information about CSA}

Before community outreach programs are delivered in a wide-scale way to try and effect macro-level change, a series of pilot/scoping studies would first need to be conducted to help identify culturally and linguistically appropriate ways of disseminating information about CSA. That is, culturally tailored programs that take into account religious, cultural, and language factors for specific groups are necessary. For example, Gilligan and Akhtar (2006) noted that in information booklets that aim to raise awareness about CSA in Muslim minority communities, it may be useful to say that "'sexual abuse is wrong and there is punishment for it, Islamically', so that the information has a 'religious sanction which makes (it) more acceptable for people to actually do something about it"” (p. 1371).

Shalhoub-Kevorkian (2000) similarly says, "there is a hadith (saying attributed to the prophet) that relates that a shepherd's daughter was forced to have sexual intercourse with a man in order to get water to drink. The victim was in the desert and deprived of water for a long time. The Prophet did not consider her submission to this blackmail as adultery (i.e. she was exonerated) but, rather, considered the blackmailer an adulterer who was punished accordingly. This hadith can be used (in information booklets about CSA) to shift blame from the victim to the aggressor" (p. 624).

Muslim participants in the study by Gilligan and Akhtar (2005), using data from seven focus groups in the UK, also highlighted "the need for separate work with men and women, age-appropriate groups, group and individual work, work with the whole family, male and female workers, work with children in all schools (including independent Muslim schools), for professionals to give particular support and reassurance to mothers accessing services, for more resources to be made available for outreach work” (p. 275), and the need for information to be accessible in a variety of languages.

More broadly, as it relates to all collectivist groups, Masehela and Pillay (2014) argue that "communities that are close knit are more likely to consider changing their ways if the emphasis in (awareness-raising) workshops is based on sharing - sharing ownership, responsibility, and values. Even parents with stereotypical thinking might reconsider whether they benefit or not. Parents may then have the courage to stand up against those who sexually abuse their children and intimidate the parents to keep quiet” (p. 33). Thus, such programs could 
capitalise on the strengths of collectivist cultures, most pertinently the value for community, to help develop group-based responsibility for protecting children and victims/survivors of CSA.

It also appears from the literature review that because awareness of CSA is low in ethnic minority communities, outreach programs would need to provide even basic information about CSA. For example, Gilligan and Akhtar (2005) conducted a 'consultation study' with participants from South Asian communities in the UK to obtain feedback on a draft information booklet that had been prepared for minority groups on CSA. One key finding was that participants asked for more "basic information about child sexual abuse and services, the rights of children and the seriousness of child sexual abuse" (p. 271).

The need for accurate information about victims/survivors of CSA is also noted. For example, Chen and Chen (2005) examined awareness of prevention programs in a large sample of 385 parents of Grade 3 children in China and found that "only $28.1 \%$ of parents agreed that "if a child has been sexually abused, there will usually be no physical evidence"” (cited in Chen et al., 2007, p. 749). This is a myth about CSA, and is problematic because it could lead to delayed identification and intervention, as well as increased risk of secondary victimisation (Tang \& Yan, 2004).

Finally, accurate information about perpetrators is also required. As an example, Ajzenstadt and Cavaglion (2005) found that "educational materials (in Israel) typically depicted that danger exists almost always outside the home from strangers" (p. 262). These materials also depicted "the family as a safe and secure place, that is supportive, loving and almost never disappointing, where children can be protected" (p. 262-263). The literature on perpetrators most commonly being those that are known to the victim (such as within their extended family network) is well established (Al-Fayez et al., 2012; Finkelhor, Hotaling, Lewis, \& Smith, 1990, cited in Choi, Choo, Choi, \& Woo, 2015; Finkelhor, 1994, cited in Usta \& Farver, 2010; Ko \& Koh, 2007; Gwirayi, 2013; Lewis, 2012; Thornton \& Veenema, 2015). Thus, accurate information is required to ensure that risk perception of familiar "trusted" adults with whom parents may be less cautious requires examination; they may actually be “exposing their children to potential abuse" (Ige \& Fawole, 2011, p. 704). As Ajzenstadt and Cavaglion (2005) go on to say, these educational materials "are encouraging children to seek help and support from families when those known to the children are the most likely perpetrators" (p. 264). Stereotypes of the "one big, happy, Jewish, family" (p. 265) as they put it, can also compound the trauma when the child victim has non-supportive responses to disclosure from family (Alaggia, 2001; Fattah \& Kabir, 2013; Gilligan \& Akhtar, 2005; Kenny \& McEachern, 2000; Lam, 2014; Lewig, Arney, Salveron, \& Barredo, 2010; Lewis, 2012; Mathews, Abrahams, \& 
Jewkes, 2013; Phasha, 2010; Rao, DiClemente, \& Ponton, 1992, cited in Futa et al., 2001; Taylor \& Norma, 2013; Yiming \& Fung, 2003). Positively, it appears that accurate information about perpetrators is advancing in Australian policy and practice. In a review of the literature and consultation with key stakeholders on best practice in school-based prevention of CSA, Smyth \& Katz (2016) found that 'stranger danger' programs were strongly discouraged in the empirical literature and by the stakeholders.

Overall, pilot studies are an example of community and participatory action research methods. In this regard, they also provide a space that can be used to help develop ways of addressing the two identified and significant cultural barriers to participation in such programs: (i) low perceived relevance of CSA to their community, and (ii) prohibitive norms regarding discussion on any matters to do with sex including abuse. The strategies developed in these studies can play to the many strengths of collectivist and minority cultures including strong family cohesion (Lesmana, Suryani, \& Tiliopoulos, 2015; Li, Ahmed, \& Zabin, 2012; Singh \& McKleroy, 2011; Tummala-Narra, 2007, cited in Okur et al., 2016; Sulimani-Aidan \& Benbenishty, 2013), community resilience and autonomy that develops from experiences of racism and discrimination (Gilligan \& Akhtar, 2006; Morris \& Balsam, 2003, cited in Walker, Hernandez, \& Davey, 2012; Singh \& McKleroy, 2011), religious factors (Haboush \& Alyan, 2013; Phasha, 2010; Yehuda, Friedman, Rosenbaurn, Labinsky, \& Schmeidler, 2007), and neighbourhoods with high social capital especially access to educational opportunities (Coulton, Crampton, Irwin, Spilsbury, \& Korbin, 2007; Maxwell, Robinson, \& Post, 2003, cited in Freeman \& Temple, 2010; Phasha, 2010; Vermeulen \& Greeff, 2015).

\subsubsection{Programs high on cultural competency}

A grave potential for judging and/or vilifying collectivist and overtly patriarchal cultures is strongly acknowledged here. However, it is outside the scope of this paper to discuss the risk and experience of racism among ethnic minority communities addressing CSA. This critical issue has been discussed in-depth elsewhere (Sawrikar \& Katz, 2017a; Sawrikar \& Katz, 2017b; Sawrikar, 2017b). Simply, for the purposes of this paper, cultural competency is identified as essential when delivering outreach programs. In the context of educational program delivery (as opposed to clinical service delivery where most attention on cultural competency in the literature lies), it is proposed that cultural competency would at least require the following elements:

- The provision of interpreters trained in matters to do with sexual assault when required

- The provision of regular training in cultural competency to staff from service organisation staff outside of the co-delivery of programs 
- The use of a 'multicultural framework', which values non-racist attitudes, practices, and policies, as well as self-reflection and awareness

- Mandatory collection of data on variables related to ethnicity (e.g. country of birth, language/s, citizenship status, refugee pathways of entry, etc.) among program participants

Of these, the use of a 'multicultural framework' and self-reflection and awareness are seen as particularly critical elements (Sawrikar \& Katz, 2017a). A multicultural framework respects (the right to) cultural differences, and self-reflection and awareness can help (especially mainstream) program providers better identify similarities between individualistic and collectivist cultures, most especially in regards to the purpose/effect of widespread acceptance of myths about CSA - to help preserve patriarchal structures. That is, the context of CSA - with the reported number of female victims significantly exceeding the reported number of male victims worldwide, and social tendencies that protect the usually male perpetrator - reveals the patriarchal elements of societies typically categorised as 'individualistic' where such trends are less overt than in their collectivist counterparts.

\subsubsection{Feminist framework}

Following on from the trends in gender differences among victims and perpetrators, this article suggests that a feminist framework may also be useful when delivering community outreach programs, because it helps establish CSA as a crime that starkly reveals the already pervasive differences in power across genders (e.g. in Western contexts, sexism is often examined in relation to discrimination in the workplace, and division of and value for housework shares, etc.). A feminist framework helps emphasise that "the social context of CSA hinges on inequality" (Vermeulen \& Greeff, 2015, p. 556), but that "an investment in women is an investment in community" (Australian Muslim Women's Centre for Human Rights; AMWCHR). Several researchers, in both Western and non-Western contexts, note the importance of using a feminist framework (Ajzenstadt \& Cavaglion, 2005; Boakye, 2009; McGuffey, 2005; Taylor \& Norma, 2013; Wang \& Heppner, 2011). In regards to increasing awareness of IPV in South Asian communities in Canada, Ahmad, Driver, McNally, and Stewart (2009) argue that "it is salient to include examples of positive role models with demonstrated equality in spousal relationships as 'success stories' (because) the use of only negatively framed messages (about patriarchy) may lead to a defensive reaction rather than a proactive response" (p. 619). By analogy, positive examples of gendered equality of children may be useful in awareness-raising campaigns of CSA. 
Importantly, male victims are silenced from disclosing their abuse for a range of reasons. For example, Thornton and Veenema (2015) say that "in Latin America, machismo attitudes make reporting victimisation difficult for young males ... (They) set a social expectation for boys and young men to be strong and resilient, (so) reporting a history of sexual abuse may be construed as an admission of weakness" (p. 439-440). "Male victims may also fear being regarded as homosexual" (Stoltenborgh, van Ijzendoorn, Euser, \& Bakermans-Kranenburg, 2011, p. 89) or "feminine" (Thornton \& Veenema, 2015, p. 436). Finally, male victims may fear they will not be believed (Lam, 2014). Consistent with this, Raissian, Dierkhising, Geiger, and Schelbe (2014) found that "if a female adolescent's (case file) alleged sexual abuse (in the US), that report was twice as likely to generate child protection system involvement compared to a male adolescent's report alleging sexual abuse, raising (serious) concerns regarding the handling of sexual abuse reports among male adolescents" (p. 11). Therefore, the use of a feminist framework may not always be useful and should be used in ways that do not risk further silencing male victims; Thornton and Veenema (2015) do say, "male victims are frequently ignored in the literature" (p. 440).

\section{Discussion}

\subsection{Summary of key findings}

The results of the literature review indicate that awareness of CSA among ethnic minority communities in Western countries like Australia is likely to be low. This is primarily due to legal and social complacency about CSA in countries of origin, which can transfer after migration. Complacency, in turn, reflects a fundamental cultural issue about the role of the state in a matter typically seen to belong to the realm of the family. Combined with widespread myths about CSA that protect and preserve patriarchal structures, people from ethnic minority communities may have low awareness and perceived threat of CSA, seeing it to be 'a Western problem'. This poses a challenge for raising awareness of CSA because outreach/educational/preventive programs - which this article suggests may be one way to increase awareness of CSA - may not be perceived as relevant to their community. This challenge is exacerbated by prohibitive norms regarding the discussion of any matters to do with sex including abuse.

Despite that raising participation in programs and awareness of CSA are likely to be difficult, such efforts are still seen to be necessary because they represent commitment to protecting children from these groups. They also represent investment in the building of social capital, so long as the investment is done with a genuine intent to engage with minority communities in empowering ways. 
Programs would need to be co-delivered by service organisations and members of ethnic minority communities who are strong advocates of human rights and social justice; this provides opportunity for the exchange of important information from both sides as well as space for culturally meaningful constructions of child safety. Programs would also need to use a 'multicultural framework' to help ensure that the safety of cultures is protected, and a 'feminist framework' in ways that do not further silence or exclude male victims/survivors of CSA. Information delivered in these programs would need to include basic information about CSA such as children's right to safety and the role of governments to protect children, as well as accurate information about CSA including who constitutes a likely perpetrator (known rather than unknown person) and myths about CSA to help dispel them. Finally, programs would need to be piloted to ensure they were culturally and linguistically tailored to specific groups.

\subsection{Significance and future research}

This review is a significant contribution to the literature because it begins to address the gap in national research on CSA and ethnic minority communities. In particular, it has explored the likelihood of current awareness of CSA in minority communities in Australia, barriers to addressing awareness, and suggestions for raising it. Future research that uses empirically rigorous methods is required to substantiate these further. Such research could include, for example, a national cross-cultural prevalence study and evaluation of outreach programs.

\subsection{Conclusion}

Overall, it is concluded that realistic goals about the effectiveness of outreach programs can help ensure their success. As Shalhoub-Kevorkian (2000) importantly points out, "inappropriate haste to use reforms and social punishment as a means of combating violence may only result in further suffering, abuse, and control of women who (already) have limited social means" (p. 632). Boakye (2009) says, "although some beliefs and practices may be difficult to change in the short-term, they nonetheless can be changed if consistently challenged through constructive engagement" (p. 954). Thus, programs designed for regular implementation across the long-term, with genuine commitment to engage with minority communities in empowering ways, may be able to increase community awareness. 


\section{References}

Abdel-Fatah, R. (2016). International Women's Day speech, Sydney.

https://newmatilda.com/2016/03/09/brown-lives-for-white-utopia/?utm_campaign

Ahmad, F., Driver, N., McNally, M. J., \& Stewart, D. E. (2009). "Why doesn’t she seek help for partner abuse?" An exploratory study with South Asian immigrant women. Social Science and Medicine, 69(4), 613-622.

Ajzenstadt, M., \& Cavaglion, G. (2005). Stories about child sexual abuse: Textual analysis of instruction manuals in Israel. Qualitative Sociology, 28(3), 255-274.

Al-Fayez, G. A., Ohaeri, J. U., \& Gado, O. M. (2012). Prevalence of physical, psychological, and sexual abuse among a nationwide sample of Arab high school students: Association with family characteristics, anxiety, depression, self-esteem, and quality of life. Social Psychiatry and Psychiatric Epidemiology, 47(1), 53-66.

Alaggia, R. (2001). Cultural and religious influences in maternal response to intrafamilial child sexual abuse: Charting new territory for research and treatment. Journal of Child Sexual Abuse, 10(2), 41-60.

Allimant, A., \& Ostapiej-Piatkowski, B., (2011). Studies, (2011). Supporting women from CALD backgrounds who are victims/survivors of sexual violence: challenges and opportunities for practitioners. Australian Centre for the Study of Sexual Assault (ACSSA) Wrap, No. 9, 1-16, Melbourne: Australian Institute of Family Studies.

AlMadani, O., Bamousa, M., Alsaif, D., Kharoshah, M. A. A., \& Alsowayigh, K. (2012). Child physical and sexual abuse in Dammam, Saudi Arabia: A descriptive case-series analysis study. Egyptian Journal of Forensic Sciences, 2(1), 33-37.

Australian Bureau of Statistics (ABS, 2016). Catalogue 2071.0: Census of Population and Housing. http://www.abs.gov.au/ausstats/abs@.nsf/Lookup/by\%20Subject/2071.0 2016 Main\%20Features Cultural\%20 Diversity\%20Article 20?OpenDocument\&ref=story

Australian Bureau of Statistics (ABS, 2012). Catalogue 1301.0: Year Book of Australia. http://www.abs.gov.au/ausstats/abs@.nsf/Lookup/1301.0Main+Features592012

Australian Muslim Women's Centre for Human Rights (AMWCHR): http://ausmuslimwomenscentre.org.au/wp-content/uploads/2014/07/AMWCHR-ChildAware.pdf 
Back, S. E., Jackson, J. L., Fitzgerald, M., Shaffer, A., Salstrom, S., \& Osman, M. M. (2003). Child sexual and physical abuse among college students in Singapore and the United States. Child Abuse and Neglect, 27(11), $1259-1275$.

Berry, J. W. (1980). Acculturation as varieties of adaptation. In A. M. Padilla (Ed.), Acculturation: Theory, models, and some new findings. Boulder, $\mathrm{CO}$ : Westview.

Boakye, K. E. (2009). Culture and nondisclosure of child sexual abuse in Ghana: A theoretical and empirical exploration. Law and Social Inquiry, 34(4), 951-979.

Bond, M. H. (2002). Reclaiming the individual from Hofstede's ecological analysis-A 20-year odyssey: Comment on Oyserman et al. (2002). Psychological Bulletin, 128, 73-77.

Bromfield, L. \& Arney, F. (2008) Developing a road map for research: Identifying priorities for a national child protection research agenda: Issues paper. Australian Institute of Family Studies, No 28.

Brophy, J., Jhutti-Johal, J. \& Owen, C. (2003). Significant harm: Child protection litigation in a multi-cultural setting. Lord Chancellor's Department Research Unit, London.

Burke, S. \& Paxman, M. (2008). Children and young people from non-English speaking backgrounds in Out of Home Care in NSW. Sydney: NSW Department of Community Services.

Cashmore, J., Higgins, D. J., Bromfield, L., \& Scott, D. A. (2006). Recent Australian child protection and out of home care research: what's been done and what needs to be done? Children Australia, 31(2), 4-11.

Chand, A., \& Thoburn, J. (2006). Research Review: Child protection referrals and minority ethnic children and families. Child and Family Social Work, 11(4), 368-377.

Chen, J. Q., \& Chen, D. G. (2005). Awareness of child sexual abuse prevention education among parents of Grade 3 elementary school pupils in Fuxin City, China. Health Education Research, 20(5), 540-547.

Chen, J., Dunne, M. P., \& Han, P. (2007). Prevention of child sexual abuse in China: Knowledge, attitudes, and communication practices of parents of elementary school children. Child Abuse and Neglect, 31(7), 747-755.

Chen, J., Dunne, M. P., \& Han, P. (2004). Child sexual abuse in China: A study of adolescents in four provinces. Child Abuse and Neglect, 28(11), 1171-1186. 
Chien, M. H. (2013). Identifying key components of an internet information system for Chinese survivors of childhood sexual abuse. Journal of Ethnic \& Cultural Diversity in Social Work, 22(3-4), 256-270.

Choi, K. S., Choo, K., Choi, J., \& Woo, Y. (2015). Understanding the dynamics of the victim-perpetrator relationship in child sexual abuse: An examination of the child sex abuse victimization data in South Korea. Asian Journal of Criminology, 10(1), 79-97.

Collings, S. J., Lindblom, L., Madu, S. N., \& Park, M. S. (2009). The cross-cultural validity of the child sexual abuse myth scale: A preliminary investigation. Journal of Psychology in Africa, 19(1), 9-18.

Collings, S, J. (1997). Development, reliability, and validity of the child sexual abuse myth scale. Journal of Interpersonal Violence, 12(5), 665-674.

Coulton, C. J., Crampton, D. S., Irwin, M., Spilsbury, J. C., \& Korbin, J. E. (2007). How neighborhoods influence child maltreatment: A review of the literature and alternative pathways. Child Abuse and Neglect, 31(11), 1117-1142.

Elbedour, S., Abu-Bader, S., Onwuegbuzie, A. J., Abu-Rabia, A., \& El-Aassam, S. (2006). The scope of sexual, physical, and psychological abuse in a Bedouin-Arab community of female adolescents: The interplay of racism, urbanization, polygamy, family honor, and the social marginalization of women. Child Abuse and Neglect, 30(3), 215-229.

Fattah, K. N., \& Kabir, Z. N. (2013). No place is safe: Sexual abuse of children in rural Bangladesh. Journal of Child Sexual Abuse, 22(8), 901-914

Finkelhor, D. (1994). Current information on the scope and nature of child sexual abuse. Future Child, 4, 31-53.

Finkelhor, D., Hotaling, G., Lewis, I., \& Smith, C. (1990). Sexual abuse in a national survey of adult men and women: prevalence, characteristics, and risk factors. Child Abuse and Neglect, 14, 19-28.

Fontes, L. (1993). Considering culture and oppression. Journal of Feminist Family Therapy, 5(1), $25-54$.

Freeman, D. H., Jr., \& Temple, J. R. (2010). Social factors associated with history of sexual assault among ethnically diverse adolescents. Journal of Family Violence, 25(3), 349-356. 
Futa, K. T., Hsu, E., \& Hansen, D. J. (2001). Child sexual abuse in Asian American families: An examination of cultural factors that influence prevalence, identification, and treatment. Clinical Psychology: Science and Practice, 8(2), 189-209.

Gibson, C., Emeka, T. Q., \& Walters, N. (2007). Sexual abuse of minors in Jamaica: Understanding predator, prey, and citizenry. Journal of Ethnicity in Criminal Justice, 5(2-3), 109-122.

Gilligan, P., \& Akhtar, S. (2006). Cultural barriers to the disclosure of child sexual abuse in Asian communities: Listening to what women say. British Journal of Social Work, 36(8), 1361-1377.

Gilligan, P., \& Akhtar, S. (2005). Child sexual abuse among Asian communities: Developing materials to raise awareness in Bradford. Practice (UK), 17(4), 267-284.

Gwirayi, P. (2013). The prevalence of child sexual abuse among secondary school pupils in Gweru, Zimbabwe. Journal of Sexual Aggression, 19(3), 253-263.

Haboush, K. L., \& Alyan, H. (2013). “Who can you tell?” Features of Arab culture that influence conceptualization and treatment of childhood sexual abuse. Journal of Child Sexual Abuse, 22(5), 499-518.

Haj-Yahia, M. M., \& Tamish, S. (2001). The rates of child sexual abuse and its psychological consequences as revealed by a study among Palestinian university students. Child Abuse and Neglect, 25(10), 1303-1327.

Henderson, A. (2007). Islam and Australia: The next phase. Sydney Institute Quarterly, 30, 9-13.

Hofstede (2001): http://www.clearlycultural.com/geert-hofstede-cultural-dimensions/individualism/

Hofstede, G. H. (1980). Culture's consequences: International differences in work-related values. Beverly Hills, Calif: Sage Publications.

Ige, O. K., \& Fawole, O. I. (2011). Preventing child sexual abuse: Parents' perceptions and practices in urban Nigeria. Journal of Child Sexual Abuse, 20(6), 695-707.

Itzhaky, H., \& York, A. S. (2001). Child sexual abuse and incest: Community-based intervention. Child Abuse and Neglect, 25(7), 959-972. 
Jewkes, R., Penn-Kekana, L., \& Rose-Junius, H. (2005). "If they rape me, I can't blame them": Reflections on gender in the social context of child rape in South Africa and Namibia. Social Science and Medicine, 61(8), $1809-1820$.

Ji, K., Finkelhor, D., \& Dunne, M. (2013). Child sexual abuse in China: A meta-analysis of 27 studies. Child Abuse and Neglect, 37(9), 613-622.

Karsli, T. A., \& Anli, I. (2011). Viewpoint to rape and self-esteem in a Turkish late-adolescent population. Paper presented at the Procedia - Social and Behavioral Sciences.

Karthiga, R. K. J., \& Ravikumar, R. (2014). Child sexual abuse in Madurai, India: A literary review and empirical study. Journal of Child Sexual Abuse, 23(6), 727-744.

Kenny, M. C., \& McEachern, A. G. (2000). Racial, ethnic, and cultural factors of childhood sexual abuse: A selected review of the literature. Clinical Psychology Review, 20(7), 905-922.

Kisanga, F., Mbwambo, J., Hogan, N., Nystrom, L., Emmelin, M., \& Lindmark, G. (2010). Perceptions of child sexual abuse: A qualitative interview study with representatives of the socio-legal system in urban Tanzania. Journal of Child Sexual Abuse, 19(3), 290-309.

Ko, C., \& Koh, C. K. (2007). The influence of abuse situation and respondent background characteristics on Korean nurses' perceptions of child sexual abuse: A fractional factorial design. International Journal of Nursing Studies, 44(7), 1165-1176.

Korbin, J. (2008). Child Neglect and Abuse across Cultures (E. U. Robinson G, Goodnow J, \& Katz I Ed. Contexts of Child Development Culture, Policy and Intervention ed.). Darwin: Charles Darwin University Press.

Korbin, J. E. (2002). Culture and child maltreatment: cultural competence and beyond. Child Abuse and Neglect, 26, 637-644.

Krug, E. G., Dahlberg, L. L., Mercy, J. A., Zwi, A. B., Lozano, R. (2002). World report on violence and health. Geneva: World Health Organisation.

Lalor, K. (2004a). Child sexual abuse in Tanzania and Kenya. Child Abuse and Neglect, 28(8), 833-844.

Lalor, K. (2004b). Child sexual abuse in sub-Saharan Africa: A literature review. Child Abuse and Neglect, 28(4), 439-460. 
Lam, K. Y. I. (2014). Factors associated with adolescents' disclosure of sexual abuse experiences in Hong Kong. Journal of Child Sexual Abuse, 23(7), 768-791.

Lesmana, C. B. J., Suryani, L. K., \& Tiliopoulos, N. (2015) Cultural considerations in the treatment of mental illness among sexually abused children and adolescents: The case of Bali, Indonesia. Vol. 2015. New Directions for Child and Adolescent Development (pp. 109-116).

Lev-Wiesel, R., \& Amir, M. (2005). Holocaust child survivors and child sexual abuse. Journal of Child Sexual Abuse, 14(2), 69-83.

Lewig, K., Arney, F., Salveron, M., \& Barredo, M. (2010). Parenting in a new culture: Working with refugee families (pp. 157-186). Cambridge: Cambridge University Press.

Lewis, I. R. (2012). At risk: The relationship between experiences of child sexual abuse and women's HIV status in Papua New Guinea. Journal of Child Sexual Abuse, 21(3), 273-294.

Li, N., Ahmed, S., \& Zabin, L. S. (2012). Association between childhood sexual abuse and adverse psychological outcomes among youth in Taipei. Journal of Adolescent Health, 50(3, Suppl), S45-S51.

Liao, M., Lee, A. S., Roberts-Lewis, A. C., Hong, J. S., \& Jiao, K. (2011). Child maltreatment in China: An ecological review of the literature. Children and Youth Services Review, 33(9), 1709-1719.

Luo, T. Y. (2000). "Marrying my rapist?!”: The cultural trauma among Chinese rape survivors. Gender and Society, 14(4), 581-597.

Madu, S. N., \& Peltzer, K. (2000). Risk factors and child sexual abuse among secondary school students in the Northern Province (South Africa). Child Abuse and Neglect, 24(2), 259-268.

Masehela, B., \& Pillay, V. (2014). Shrouds of silence: A case study of sexual abuse in schools in the Limpopo Province in South Africa. Perspectives in Education, 32(3), 22-35.

Mathews, B., Walsh, K., Dunne, M., Katz, I., Arney, F., Higgins, D.,.. \& Bates, S. (2016). Scoping study for research into the prevalence of child abuse in Australia: report to the Royal Commission into Institutional Responses to Child Sexual Abuse. Sydney: Social Policy Research Centre, UNSW Australia in partnership with Australian Institute of Family Studies, Queensland University of Technology and the Australian Centre for Child Protection (University of South Australia). 
Mathews, S., Abrahams, N., \& Jewkes, R. (2013). Exploring mental health adjustment of children post sexual assault in South Africa. Journal of Child Sexual Abuse, 22(6), 639-657.

Maxwell, C. D., Robinson, A. L., \& Post, L. A. (2003). The nature and predictors of sexual victimization and offending among adolescents. Journal of Youth and Adolescence, 32, 465-477.

McGuffey, C. (2008). "Saving masculinity”: Gender reaffirmation, sexuality, race, and parental responses to male child sexual abuse. Social Problems, 55(2), 216-237.

McGuffey, C. (2005). Engendering trauma: Race, class, and gender reaffirmation after child sexual Abuse. Gender and Society, 19(5), 621-643.

Meel, B. L. (2003). 1. The myth of child rape as a cure for HIV/AIDS in Transkei: A case report. Medicine, Science and the Law, 43(1), 85-88.

Meetoo, V., \& Mirza, H. S. (2007). “There is nothing ‘honourable’ about honour killings”: Gender, violence and the limits multiculturalism. Women's Studies International Forum, 30(3), 187-200.

Mildred, J., \& Plummer, C. A. (2009). Responding to child sexual abuse in the United States and Kenya: Child protection and children's rights. Children and Youth Services Review, 31(6), 601-608.

Miller, A. B., \& Cross, T. (2006). Ethnicity in child maltreatment research: A replication of Behl et al.'s content analysis. Child Maltreatment, 11(1), 16-26.

Moher, D., Liberati, A., Tetzlaff, J., Altman, D. G., \& The PRISMA Group. (2009). Preferred Reporting Items for Systematic Reviews and Meta-Analyses: The PRISMA Statement. PLoS Med, 6(7), e1000097.

Morris, J. F., \& Balsam, K. F. (2003). Lesbian and bisexual women's experiences of victimization: Mental health, revictimization, and sexual identity development. Journal of Lesbian Studies, 7, 67-85.

Narducci, T. (1992). Race, culture and child protection. In: Key issues in child protection: For health visitors and nurses (eds C. Cloke \& J. Naish). Longman Group, Harlow, Essex.

O’Hagan, K. (1999). Culture, cultural identity, and cultural sensitivity in child and family social work. Child and Family Social Work, 4(4), 269-281. 
Okur, P., van der Knaap, L. M., \& Bogaerts, S. (2016). Ethnic differences in help-seeking behaviour following child sexual abuse: a multi-method study. Culture, Health and Sexuality, 18(1), 99-111.

Owusu-Bempah, K., \& Howitt, D. (2000). Psychology beyond Western perspectives: London: Wiley-Blackwell.

Pasura, D., Jones, A. D., Hafner, J. A. H., Maharaj, P. E., Nathaniel-DeCaires, K., \& Johnson, E. J. (2012).

Competing meanings of childhood and the social construction of child sexual abuse in the Caribbean.

Childhood, 20(2), 200-214.

Pether, P. (2009). What is due to others: Speaking and signifying subject(s) of rape law. Griffith Law Review, $18(2), 237-258$.

Phasha, T. N. (2010). Educational resilience among African survivors of child sexual abuse in South Africa. Journal of Black Studies, 40(6), 1234-1253.

Raissian, K. M., Dierkhising, C. B., Geiger, J. M., \& Schelbe, L. (2014). Child maltreatment reporting patterns and predictors of substantiation: Comparing adolescents and younger children. Child Maltreatment, 19(1), 3-16.

Rao, K., DiClemente, R. J., \& Ponton, L. E. (1992). Child sexual abuse of Asians compared with other populations. Journal of the American Academy of Child and Adolescent Psychiatry, 31, 880-886.

Reavey, P., Ahmed, B., \& Majumdar, A. (2006). 'How can we help when she won't tell us what's wrong?' Professionals working with South Asian women who have experienced sexual abuse. Journal of Community and Applied Social Psychology, 16(3), 171-188.

Reid, S. D., Reddock, R., \& Nickenig, T. (2014). Breaking the silence of child sexual abuse in the Caribbean: A community-based action research intervention model. Journal of Child Sexual Abuse, 23(3), 256-277.

Rwanyonga, T. C., Mike, M., \& Nakubulwa, A. (2009). Child sexual abuse in schools: Preliminary indication for enhancement of universal primary education and community (EUPEC Project) - Uganda. Journal of Psychology in Africa, 19(1), 105-106.

Salter, M. (2014). Multi-perpetrator domestic violence. Trauma, Violence, and Abuse: A Review Journal, 15(2), $102-112$.

Sawrikar, P. (2017a). Working effectively with ethnic minorities and across cultures in Western child protection systems. UK: Routledge. 
Sawrikar, P. (2017b). Doing ‘everyday sociology’ to inform child protection work on child sexual abuse (CSA) in ethnic minority communities and conceptualisations of racism. (Under review).

Sawrikar, P. \& Katz, I. (2017a). The treatment needs of victims/survivors of child sexual abuse (CSA) from ethnic minority communities: A literature review and suggestions for practice. Children and Youth Services Review, doi: 10.1016/j.childyouth.2017.06.021.

Sawrikar, P. \& Katz, I. (2017b). Barriers to disclosing child sexual abuse (CSA) in ethnic minority communities: A review of the literature and implications for practice in Australia. (In preparation).

Sawrikar, P. \& Katz, I. (2010). "Only White people can be racist": What does power have to do with prejudice? Cosmopolitan Civil Societies, 2(1), 80-99.

Sawrikar, P. \& Katz, I. (2009). How useful is the term "Culturally and Linguistically Diverse (CALD)" in the Australian social policy discourse? Refereed conference paper, Australian Social Policy Conference (ASPC), Sydney.

Sawrikar, P. \& Katz, I. (2008). Enhancing family and relationship service accessibility and delivery to culturally and linguistically diverse (CALD) families in Australia. Issues paper prepared for the Australian Family Relationships Clearinghouse (AFRC), Issues No. 3.

Sawrikar, P., \& Hunt, C. J. (2005). The relationship between mental health, cultural identity and cultural values in non-English speaking background (NESB) Australian adolescents. Behaviour Change, 22(2), 97-113.

Shalhoub-Kevorkian, N. (2000). Blocking her exclusion: A contextually sensitive model of intervention for handling female abuse. Social Service Review, 74(4), 620-634.

Shang, X., \& Katz, I. (2014). Missing elements in the protection of children: Three cases from China. Journal of Social Service Research, 40(4), 545-559.

Sherer, M. (2009). The nature and correlates of dating violence among Jewish and Arab youths in Israel. Journal of Family Violence, 24(1), 11-26.

Singh, A. A. (2009). Helping South Asian immigrant women use resilience strategies in healing from sexual abuse: A call for a culturally relevant model. Women and Therapy, 32(4), 361-376. 
Singh, A. A., \& McKleroy, V. S. (2011). "Just getting out of bed is a revolutionary act": The resilience of transgender people of color who have survived traumatic life events. Traumatology, 17(2), 34-44.

Singh, A. A., Hays, D. G., Chung, Y. B., \& Watson, L. (2010). South Asian immigrant women who have survived child sexual abuse: Resilience and healing. Violence Against Women, 16(4), 444-458.

Smyth, C., \& Katz, I. (2016). Child protection and respectful relationships education and best practice in school settings - Literature review and stakeholder consultation: Prepared for NSW Department of Education. Sydney: Social Policy Research Centre (SPRC), University of New South Wales (UNSW).

Sossou, M-A., \& Yogtiba, J. A. (2009). Abuse of children in West Africa: Implications for social work education and practice. The British Journal of Social Work, 39(7), 1218-1234.

Stoltenborgh, M., van Ijzendoorn, M. H., Euser, E. M., \& Bakermans-Kranenburg, M. J. (2011). A global perspective on child sexual abuse: Meta-analysis of prevalence around the world. Child Maltreatment, 16(2), 79-101.

Sugue-Castillo, M. (2009). Legal outcomes of sexually abused children evaluated at the Philippine General Hospital Child Protection Unit. Child Abuse and Neglect, 33(3), 193-202.

Sulimani-Aidan, Y., \& Benbenishty, R. (2013). Child maltreatment reports in Israel: The intersection between community socioeconomic characteristics and ethnicity. American Journal of Orthopsychiatry, 83(1), 29-36.

Tang, C. S. K., \& Yan, E. C. W. (2004). Intention to participate in child sexual abuse prevention programs: A study of Chinese adults in Hong Kong. Child Abuse and Neglect, 28(11), 1187-1197.

Taylor, S., \& Norma, C. (2013). The ties that bind: Family barriers for adult women seeking to report childhood sexual assault in Australia. Women's Studies International Forum, 37, 114-124.

Thoburn, J., Chand, A., \& Procter, J. (2005). Child welfare services for minority ethnic families: The research reviewed. Jessica Kingsley: London.

Thornton, C. P., \& Veenema, T. G. (2015). Children seeking refuge: A review of the escalating humanitarian crisis of child sexual abuse and HIV/AIDS in Latin America. JANAC: Journal of the Association of Nurses in AIDS Care, 26(4), 432-442. 
Tishelman, A. C., \& Geffner, R. (2010). Forensic, cultural, and systems issues in child sexual abuse Cases-Part 1: An Introduction. Journal of Child Sexual Abuse, 19(5), 485-490.

Triandis, H. C. (1990). Theoretical concepts that are applicable to the analysis of ethnocentricism. In R. W. Brislin (Ed.), Applied cross-cultural psychology. New York: Sage.

Tummala-Narra, P. (2007). Conceptualizing trauma and resilience across diverse contexts: A multicultural perspective. Journal of Aggression, Maltreatment and Trauma, 14(1-2), 33-53.

UNICEF (United Nations International Children's Emergency Fund). (2008). UNICEF Child Protection Strategy. New York: UNICEF.

Usta, J., \& Farver, J. (2010). Child sexual abuse in Lebanon during war and peace. Child: Care, Health and Development, 36(3), 361-368.

Vermeulen, T., \& Greeff, A. P. (2015). Family resilience resources in coping with child sexual abuse in South Africa. Journal of Child Sexual Abuse, 24(5), 555-571.

Walker, M. D., Hernandez, A. M., \& Davey, M. (2012). Childhood sexual abuse and adult sexual identity formation: Intersection of gender, race, and sexual orientation. American Journal of Family Therapy, 40(5), 385-398.

Walker, J. S., \& Bright, J. A. (2009). False inflated self-esteem and violence: A systematic review and cognitive model. The Journal of Forensic Psychiatry and Psychology, 20, 1-32.

Wang, Y-W., \& Heppner, P. (2011). A qualitative study of childhood sexual abuse survivors in Taiwan: Toward a transactional and ecological model of coping. Journal of Counseling Psychology, 58(3), 393-409.

Welbourne, P. (2002). Culture, children's rights and child protection. Child Abuse Review, 11(6), 345-358.

Whitaker, D. J., Baker, C. K., Pratt, C., Reed, E., Suri, S., Pavlos, C., Nagy, B. J., \& Silverman, J. (2007). A network model for providing culturally competent services for intimate partner violence and sexual violence. Violence Against Women, 13(2), 190-209.

Williams, C. (2014). The catalysers? 'black' professionals and the anti-racist movement In Race, racism and social work: Contemporary issues and debates. Bristol, UK: Policy Press. 
Yehuda, R., Friedman, M., Rosenbaurn, T. Y., Labinsky, E., \& Schmeidler, J. (2007). History of past sexual abuse in married observant Jewish women. The American Journal of Psychiatry, 164(11), 1700-1706.

Yiming, C., \& Fung, D. (2003). Child sexual abuse in Singapore with special reference to medico-legal implications: A review of 38 cases. Medicine, Science and the Law, 43(3), 260-266.

Yoshihama, M., \& Horrocks, J. (2010). Risk of intimate partner violence: Role of childhood sexual abuse and sexual initiation in women in Japan. Children and Youth Services Review, 32(1), 28-37. 
Appendix A: Summary of articles obtained from the PRISMA process and used to answer RQs 1 and 2

\begin{tabular}{|c|c|c|c|}
\hline AUTHORS & $\begin{array}{l}\text { COUNTRY/IES STUDY } \\
\text { CONDUCTED IN }\end{array}$ & METHOD & RIGOROUS \\
\hline \multicolumn{4}{|c|}{ Includes or mostly based in Western contexts } \\
\hline 1. Alaggia (2001) & Canada (Various) & Qualitative & $\begin{array}{l}\text { Thematic saturation } \\
\text { reached }\end{array}$ \\
\hline $\begin{array}{l}\text { 2. } \text { Allimant \& Ostapiej- } \\
\text { Piatkowski (2011) }\end{array}$ & Australia (Various) & $\begin{array}{l}\text { Secondary analysis } \\
\text { (literature review) }\end{array}$ & \\
\hline 3. Back et al. (2003) & Singapore/USA & Quantitative & \\
\hline 4. Chand \& Thoburn (2006) & UK (South Asians) & $\begin{array}{l}\text { Secondary analysis } \\
\text { (literature review) }\end{array}$ & \\
\hline 5. Freeman \& Temple (2010) & USA (Various) & Quantitative & $\begin{array}{l}\text { Large, representative } \\
\text { sample }(\mathrm{n}=1634)\end{array}$ \\
\hline 6. Futa et al. (2001) & USA (East Asians) & $\begin{array}{l}\text { Secondary analysis } \\
\text { (literature review) }\end{array}$ & \\
\hline 7. Gilligan \& Akhtar (2006) & UK (South Asians) & Qualitative & \\
\hline 8. Gilligan \& Akhtar (2005) & UK (South Asians) & Qualitative & \\
\hline 9. Haboush \& Alyan (2013) & USA (Arabs) & $\begin{array}{l}\text { Secondary analysis } \\
\text { (literature review) }\end{array}$ & \\
\hline 10. Henderson (2007) & Australia (Muslims) & $\begin{array}{l}\text { Secondary analysis } \\
\text { (Commentary) }\end{array}$ & \\
\hline $\begin{array}{l}\text { 11. Kenny \& McEachern } \\
\text { (2000) }\end{array}$ & USA (Various) & $\begin{array}{l}\text { Secondary analysis } \\
\text { (literature review) }\end{array}$ & \\
\hline 12. Lev-Wiesel \& Amir (2005) & Israel/USA & Qualitative & \\
\hline 13. Liao et al. (2011). & China/USA & $\begin{array}{l}\text { Secondary analysis } \\
\text { (literature review) }\end{array}$ & \\
\hline 14. McGuffey (2008) & USA (Various) & Qualitative & $\begin{array}{l}\text { Large sample }(n=62) ; \\
\text { longitudinal }\end{array}$ \\
\hline 15. McGuffey (2005) & USA (Various) & Qualitative & Large sample $(n=60)$ \\
\hline
\end{tabular}




\begin{tabular}{|c|c|c|c|}
\hline $\begin{array}{l}\text { 16. Mildred \& Plummer } \\
\text { (2009) }\end{array}$ & USA/Kenya & $\begin{array}{l}\text { Secondary analysis } \\
\text { (literature review/ } \\
\text { commentary) }\end{array}$ & \\
\hline 17. Okur et al. (2016) & $\begin{array}{l}\text { Netherlands (Dutch } \\
\text { Antillean/Surinamese and } \\
\text { Moroccan/Turkish) }\end{array}$ & & $\begin{array}{l}\text { Mixed methods - } \\
\text { methodological rigour }\end{array}$ \\
\hline 18. Raissian et al. (2014) & USA (Various) & Quantitative & $\begin{array}{l}\text { Large, nationally } \\
\text { representative sample }\end{array}$ \\
\hline 19. Reavey et al. (2006) & UK (South Asians) & Qualitative & \\
\hline 20. Salter (2014) & Australia (Muslims) & $\begin{array}{l}\text { Secondary analysis } \\
\text { (literature review) }\end{array}$ & \\
\hline 21. Singh (2009) & USA (South Asians) & $\begin{array}{l}\text { Secondary analysis } \\
\text { (literature review) }\end{array}$ & \\
\hline 22. Singh \& McKleroy (2011) & $\begin{array}{l}\text { USA (Transgender people } \\
\text { of colour) }\end{array}$ & Qualitative & \\
\hline 23. Stoltenborgh et al. (2011) & Netherlands & & $\begin{array}{l}\text { Quantitative (meta- } \\
\text { analysis) - } \\
\text { methodological rigour }\end{array}$ \\
\hline 24. Taylor \& Norma (2013) & Australia (Various) & Qualitative & \\
\hline $\begin{array}{l}\text { 25. Thornton \& Veenema } \\
\text { (2015) }\end{array}$ & USA (Latin Americans) & $\begin{array}{l}\text { Secondary analysis } \\
\text { (literature review) }\end{array}$ & \\
\hline $\begin{array}{l}\text { 26. Tishelman \& Geffner } \\
\text { (2010) }\end{array}$ & USA (Various) & $\begin{array}{l}\text { Secondary analysis } \\
\text { (editorial } \\
\text { introduction) }\end{array}$ & \\
\hline 27. Walker et al. (2012) & USA (Various) & Qualitative & \\
\hline 28. Wang \& Heppner (2011) & USA (Taiwanese) & Qualitative & Confirmability checked \\
\hline 29. Yehuda et al. (2007) & USA (Jewish) & Quantitative & \\
\hline \multicolumn{4}{|c|}{ Mostly based in non-Western contexts } \\
\hline
\end{tabular}




\begin{tabular}{|c|c|c|c|}
\hline $\begin{array}{l}\text { 30. Ajzenstadt \& Cavaglion } \\
\text { (2005) }\end{array}$ & Israel & Qualitative & \\
\hline 31. Al-Fayez et al. (2012) & Kuwait & Quantitative & $\begin{array}{l}\text { Large, representative } \\
\text { sample }(\mathrm{n}=4467)\end{array}$ \\
\hline 32. AlMadani et al. (2012) & Saudi Arabia & Quantitative & \\
\hline 33. Boakye (2009) & Ghana & Quantitative & \\
\hline 34. Chen et al. (2007) & China & Quantitative & $\begin{array}{l}\text { Large, representative } \\
\text { sample }(n=652)\end{array}$ \\
\hline 35. Chen et al. (2004) & China & Quantitative & $\begin{array}{l}\text { Large, representative } \\
\text { sample }(n=2300)\end{array}$ \\
\hline 36. Chien (2013) & China & Quantitative & \\
\hline 37. Choi et al. (2015) & South Korea & Quantitative & \\
\hline 38. Collings et al. (2009) & $\begin{array}{l}\text { South Africa, Korea, } \\
\text { Sweden }\end{array}$ & Quantitative & $\begin{array}{l}\text { Large sample }(n=600 ; \\
200 \text { per country })\end{array}$ \\
\hline 39. Elbedour et al. (2006) & Israel & Quantitative & \\
\hline 40. Fattah \& Kabir (2013) & Bangladesh & Quantitative & Large sample $(\mathrm{n}=713)$ \\
\hline 41. Gibson et al. (2007) & Jamaica & $\begin{array}{l}\text { Secondary analysis } \\
\text { (literature review) }\end{array}$ & \\
\hline 42. Gwirayi (2013) & Zimbabwe & Quantitative & \\
\hline $\begin{array}{l}\text { 43. Haj-Yahia \& Tamish } \\
\text { (2001) }\end{array}$ & Palestine & Quantitative & \\
\hline 44. Ige \& Fawole (2011) & Nigeria & Quantitative & \\
\hline 45. Itzhaky \& York (2001) & Israel & Qualitative & \\
\hline 46. Jewkes et al. (2005) & South Africa & Qualitative & $\begin{array}{l}\text { Large sample }(\mathrm{n}=77 \\
\text { interviews and } 3 \text { small } \\
\text { group discussions) }\end{array}$ \\
\hline 47. Ji et al. (2013) & China & Quantitative & \\
\hline 48. Karsli \& Anli (2011) & Turkey & Quantitative & \\
\hline
\end{tabular}




\begin{tabular}{|c|c|c|c|}
\hline $\begin{array}{l}\text { 49. Karthiga \& Ravikumar } \\
\text { (2014) }\end{array}$ & India & & $\begin{array}{l}\text { Mixed method - } \\
\text { methodological rigour }\end{array}$ \\
\hline 50. Kisanga et al. (2010) & Tanzania & Qualitative & Trustworthiness checked \\
\hline 51. Ko \& Koh (2007) & Korea & Quantitative & Large sample $(\mathrm{n}=1029)$ \\
\hline 52. Lalor (2004a) & Sub-Saharan Africa & $\begin{array}{l}\text { Secondary analysis } \\
\text { (literature review) }\end{array}$ & \\
\hline 53. Lalor (2004b) & Tanzania/Kenya & & $\begin{array}{l}\text { Mixed method - } \\
\text { methodological rigour }\end{array}$ \\
\hline 54. Lam (2014) & Hong Kong & Quantitative & Large sample $(n=830)$ \\
\hline 55. Lesmana et al. (2015) & Indonesia & Qualitative & \\
\hline 56. Lewis (2012) & Papua New Guinea & & $\begin{array}{l}\text { Mixed method - } \\
\text { methodological rigour }\end{array}$ \\
\hline 57. Li et al. (2012) & Taipei & Quantitative & $\begin{array}{l}\text { Large, representative } \\
\text { sample }(n=4084)\end{array}$ \\
\hline 58. Luo (2000) & Taiwan & Qualitative & \\
\hline 59. Madu \& Peltzer (2000) & South Africa & Quantitative & \\
\hline 60. Masehela \& Pillay (2014) & South Africa & Qualitative & \\
\hline 61. Mathews et al. (2013) & South Africa & & $\begin{array}{l}\text { Mixed method - } \\
\text { methodological rigour }\end{array}$ \\
\hline 62. Meel (2003) & South Africa & Qualitative & \\
\hline 63. Pasura et al. (2012) & Caribbean (6 countries) & Qualitative & $\begin{array}{l}\text { Large sample }(\mathrm{n}=120 \\
\text { stakeholder consultations } \\
+859 \text { survey } \\
\text { respondents + } 36 \text { focus } \\
\text { group discussions + } 110 \\
\text { interviews (policy- } \\
\text { makers, practitioners and }\end{array}$ \\
\hline
\end{tabular}




\begin{tabular}{|c|c|c|c|}
\hline & & & clinicians) \\
\hline 64. Phasha (2010) & South Africa & Qualitative & Trustworthiness checked \\
\hline 65. Reid et al. (2014) & Trinidad and Tobago & & $\begin{array}{l}\text { Mixed methods - } \\
\text { methodological rigour } \\
\text { Large sample ( } \mathrm{n}=1236 \\
\text { quant component) }\end{array}$ \\
\hline 66. Rwanyonga et al. (2009) & Uganda & Qualitative & $\begin{array}{l}\text { Large sample }(\mathrm{n}=442 \\
\text { pupils }+81 \text { teachers })\end{array}$ \\
\hline $\begin{array}{l}\text { 67. Shalhoub-Kevorkian } \\
\text { (2000) }\end{array}$ & Palestine & $\begin{array}{l}\text { Secondary analysis } \\
\text { (literature review) }\end{array}$ & \\
\hline 68. Sherer (2009) & Israel & Quantitative & Large sample $(\mathrm{n}=1357)$ \\
\hline 69. Sossou \& Yogtiba (2009) & West Africa & $\begin{array}{l}\text { Secondary analysis } \\
\text { (literature review) }\end{array}$ & \\
\hline 70. Sugue-Castillo (2009) & Philippines & & $\begin{array}{l}\text { Mixed methods - } \\
\text { methodological rigour }\end{array}$ \\
\hline $\begin{array}{l}\text { 71. Sulimani-Aidan \& } \\
\text { Benbenishty (2013) }\end{array}$ & Israel & Quantitative & \\
\hline 72. Tang \& Yan (2004) & Hong Kong & Quantitative & Large sample $(n=1606)$ \\
\hline 73. Usta \& Farver (2010) & Lebanon & Quantitative & Large sample $(\mathrm{n}=1028)$ \\
\hline $\begin{array}{l}\text { 74. Vermeulen \& Greeff } \\
\text { (2015) }\end{array}$ & South Africa & Qualitative & \\
\hline 75. Yiming \& Fung (2003) & Singapore & Quantitative & \\
\hline $\begin{array}{l}\text { 76. Yoshihama \& Horrocks } \\
\text { (2010) }\end{array}$ & Japan & Quantitative & Large sample $(\mathrm{n}=1371)$ \\
\hline
\end{tabular}

